\title{
Robust Model Predictive Control Paradigm for Automatic Voltage Regulators against Uncertainty Based on Optimization Algorithms
}

\author{
Mahmoud Elsisi 1,2 ${ }^{\mathbb{D}}$, Minh-Quang Tran ${ }^{1,3}{ }^{\mathbb{D}}$, , Hany M. Hasanien ${ }^{4} \mathbb{D}$, Rania A. Turky ${ }^{5}$, Fahad Albalawi ${ }^{6}(\mathbb{D}$ \\ and Sherif S. M. Ghoneim ${ }^{6, *(\mathbb{D})}$ \\ 1 Industry 4.0 Implementation Center, Center for Cyber-Physical System Innovation, National Taiwan \\ University of Science and Technology, Taipei 10607, Taiwan; mahmoud.elsisi@mail.ntust.edu.tw (M.E.); \\ minhquang.tran@mail.ntust.edu.tw (M.-Q.T.) \\ 2 Department of Electrical Engineering, Faculty of Engineering at Shoubra, Benha University, \\ Cairo 11629, Egypt \\ 3 Department of Mechanical Engineering, Thai Nguyen University of Technology, $3 / 2$ Street, Tich Luong Ward, \\ Thai Nguyen 250000, Vietnam \\ 4 Electrical Power and Machines Department, Faculty of Engineering, Ain Shams University, \\ Cairo 11517, Egypt; hany_mohamed@eng.asu.edu.eg \\ 5 Electrical Engineering Department, Faculty of Engineering and Technology, Future University in Egypt, \\ Cairo 11835, Egypt; rania.turky@fue.edu.eg \\ 6 Department of Electrical Engineering, College of Engineering, Taif University, Taif 21944, Saudi Arabia; \\ F.albiloi@tu.edu.sa \\ updates \\ * Correspondence: s.ghoneim@tu.edu.sa
}

Citation: Elsisi, M.; Tran, M.-Q.; Hasanien, H.M.; Turky, R.A.; Albalawi, F.; Ghoneim, S.S.M. Robust Model Predictive Control Paradigm for Automatic Voltage Regulators against Uncertainty Based on Optimization Algorithms. Mathematics 2021, 9, 2885. https:// doi.org/10.3390/math9222885

Academic Editors: Chuangyin Dang and Siyang Gao

Received: 27 September 2021

Accepted: 10 November 2021

Published: 12 November 2021

Publisher's Note: MDPI stays neutral with regard to jurisdictional claims in published maps and institutional affiliations.

Copyright: (c) 2021 by the authors. Licensee MDPI, Basel, Switzerland. This article is an open access article distributed under the terms and conditions of the Creative Commons Attribution (CC BY) license (https:// creativecommons.org/licenses/by/ $4.0 /)$.

\begin{abstract}
This paper introduces a robust model predictive controller (MPC) to operate an automatic voltage regulator (AVR). The design strategy tends to handle the uncertainty issue of the AVR parameters. Frequency domain conditions are derived from the Hermite-Biehler theorem to maintain the stability of the perturbed system. The tuning of the MPC parameters is performed based on a new evolutionary algorithm named arithmetic optimization algorithm (AOA), while the expert designers use trial and error methods to achieve this target. The stability constraints are handled during the tuning process. An effective time-domain objective is formulated to guarantee good performance for the AVR by minimizing the voltage maximum overshoot and the response settling time simultaneously. The results of the suggested AOA-based robust MPC are compared with various techniques in the literature. The system response demonstrates the effectiveness and robustness of the proposed strategy with low control effort against the voltage variations and the parameters' uncertainty compared with other techniques.
\end{abstract}

Keywords: automatic voltage regulator; evolutionary techniques; model predictive control; robustness

\section{Introduction}

Stability of the terminal voltage represents a critical issue in the implementation of advanced electrical grids such as microgrids and smart grids due to the diversity of the generation systems $[1,2]$. The electrical devices are manufactured at the specified voltage recorded in each country and can stand a little variation in the voltage; otherwise the device is damaged or the lifetime of the device decreases [3]. The voltage of the generator can be stabilized through the automatic voltage regulator (AVR) [4]. The improvement of the voltage response with high damping characteristics and zero steady-state error faces a great challenge due to the uncertainty of the AVR system.

Recently, various control strategies have been applied to the AVR systems such as the traditional proportional-integral-derivative (PID) controller, $\mathrm{H} \infty$ control strategy, sliding mode control, fuzzy logic (FL) control, and artificial neural network (ANN) [5-7]. In [8], a PID controller is introduced based on the whale optimization algorithm (WOA) and water 
cycle algorithm (WCA) for an AVR. The parameters of the PID controller are obtained by the WOA and the WCA based on minimizing the integral square error. The anarchic society optimization (ASO) algorithm is utilized based on minimizing the integral time absolute error in order to adjust the gains of the PID controller for an AVR system in [9]. In [10] a PID controller based on the cuckoo search algorithm (CSA) is performed for an AVR system. In [11,12], a tree seed algorithm (TSA) and an improved kidney-inspired algorithm (KIA) are utilized for the tuning of the PID controller of AVR. Furthermore, the AVR controller is tuned by an intelligent algorithm inspired based on the propagation, refraction, and breaking operations, and named a water wave optimization (WWO) in [13]. However, the PID controller is a traditional controller and cannot stand for the systems control constraints, voltage variations, and disturbances [14]. In [15,16], Jaya optimization algorithm (JOA) and gradient-based optimization (GBO) algorithm are introduced for the tuning of a fractional-order PID controller for AVR. In addition, a fractional-order PID including derivative with filter factor is adjusted based on equilibrium optimizer (EO) for AVR in [17]. In [18,19], a fractional PID controller for an AVR system is designed using particle swarm optimization (PSO) algorithm. The fractional representation for the PID terms requires complex mathematical forms and increases the order of the AVR system. In [20], a sliding mode control (SMC) is dedicated for voltage control in a microgrid. In [21], a SMC with $\mathrm{H} \infty$ control is introduced for the voltage regulation of a two-level grid under different load conditions. The chattering due to the fast switching during the control law represents the main issue against the implementation of the SMC approach. Furthermore, the $\mathrm{H} \infty$ controller doubles the order of the system which leads to unaccepted performance in some load conditions. A FL control approach is dedicated to voltage regulation in a distribution network [22]. In [23], a gain-scheduling control scheme combining with FL control is performed for the voltage regulation in a microgrid including distributed generations (DGs). A FL control approach is introduced for the voltage regulation of power transformers in [24]. The application of the FL control systems requires proper adjusting for the membership functions to provide the good performance. Furthermore, the FL control requires an expensive computing power that leads to complications in the implementation process. The voltage regulation is carried out for grid-tied solar photovoltaics (PV) based on an adaptive neuro-fuzzy inference system (ANFIS) combining with PID controller in [25]. In [26], ANN is dedicated to voltage control in a distributed power system. A voltage regulation scheme is introduced for a buck converter utilizing an ANN combined with a predictive controller in [27]. The main issue against the implementation of the ANNs is demonstrated in the availability of the proper training data to prove a good performance. Among the recent control approaches, model predictive control (MPC) is demonstrated as an optimization-based control strategy to handle the control constraints and parameters uncertainty to provide good performance in different engineering applications [28-33]. In [34], stabilization of the voltage fluctuation is carried out by utilizing an MPC for power distribution systems. Distributed MPC is utilized to stabilize voltages within permissible limits in a connected power system [35,36]. In [37], an MPC is dedicated to voltage regulation with the distributed generators (DGs) conjunction. Centralized MPC is introduced for voltage control in a distributed power system in [38]. However, proper tuning is necessary for MPC parameters including; the prediction horizon, control horizon, sampling time, and the weighting factors to enhance the system performance [39,40]. Artificial intelligence (AI) algorithms can deal with the optimization issue of the controller gains to enhance the system performance [41,42]. The trapping in a local minimum and the adjustable factors represent the main challenge against the implementation of the AI algorithms. Among AI algorithms, an algorithm termed arithmetic optimization algorithm (AOA) is developed as an effective optimization algorithm utilizing few adjustable factors and a global search strategy [43-45]. There are different versions of AOA utilized for various engineering problems [46-50]. In this paper, the original AOA is selected to tune the parameters of the MPC because this algorithm requires few adjustable parameters that enhance the performance of the AVR with a fast convergence rate and overcome the trapping in local optima 
issue instead of other algorithms. The aforementioned optimization algorithms do not take into account the AVR parameters uncertainties in a systematic strategy. The robustness issue represents the main challenge to the AVR system due to the uncertainties of the parameters. The robustness issue means that the controller must tackle the uncertainties of the plant parameters.

This paper solves the MPC robustness issue by handling the parameters' uncertainty of the AVR according to derived frequency-domain constraints using the Hermite-Biehler theorem. The gains of the MPC are tuned based on the AOA, while the expert designers use the trial-and-error methods to achieve such a target. The suggested AOA is applied to adjust the MPC by minimizing a developed figure of demerit (FoD) objective function. The developed FoD objective function can accomplish the decreasing of the response settling time and the voltage maximum overshoot simultaneously. The suggested AOA-based robust MPC is evaluated with the recent works for AVR including PID controller based on the artificial bee colony (ABC) algorithm [51], non-dominated sorting genetic algorithm II (NSGA II) [52], multi-objective extremal optimization (MOEO) [53], future search algorithm (FSA) [54], and robust multi-objective PID controller [55]. Several tests are conducted to emphasize the robustness characteristic of the suggested AOA-based robust MPC against the variations of the voltage and the parameters' uncertainty.

The following points conclude the main contributions of this research work,

- A new robust control strategy is introduced for the AVR to handle the parameters uncertainty issue and voltage variations.

- The stability of the perturbed AVR system is proved according to derived frequencydomain constraints using the Hermite-Biehler theorem during the design of MPC.

- The factors of the MPC are tuned based on an intelligent algorithm named AOA rather than the trial-and-error methods.

- A developed figure of demerit objective function is introduced to handle the decreasing of the response settling time and the voltage maximum overshoot simultaneously.

- $\quad$ The proposed AOA-based robust MPC is compared with ABC algorithm [51], NSGA II [52], MOEO algorithm [53], FSA [54], and robust multi-objective PID controller [55].

- The system response confirms the robustness characteristic of the developed AOA-based robust MPC against the variations of the voltage and the parameters' uncertainty compared with other techniques.

The manuscript is structured as follows: Section 2 formulates the AVR model with MPC. Section 3 describes the robust MPC Formulation. Section 4 introduces an overview about the arithmetic optimization algorithm. Section 5 presents the results and the discussions of the AVR system. At the end, the conclusion of the proposed work is provided in Section 6.

\section{Description of AVR System}

The AVR is utilized to regulate the voltage, in which a constant voltage can be obtained by taking the fluctuating voltage. The AVR system can improve the stability of the dynamic generator angle and maintain the operation of the machine through steady-state stability. In addition, the regulation of the DC excitation voltage is utilized to ensure that the permissible limit of the terminal voltage remains for the synchronous machine. Figure 1 illustrates the proposed scheme of the AVR system [4]. It shows that the AVR system consists of an amplifier node, exciter component, generator part, and sensor module. In this study, linear models are utilized for all four components of the AVR system instead of nonlinearity sources and exciter saturation limits. A diagram of a stationary excitation system with the controlled rectifier excitation type is presented in Figure 1a. In this system, the static rectified is controlled to regulate the excitation power. The excitation current is directly applied to the main generator via a slip ring. In order to obtain the actual values of the current and voltage without the noise, the sensor module including the potential transformer (PT) and current transformer (CT) is designed as shown in Figure 1a. Moreover, a block diagram of developed predictive controlled AVR system is presented 
in Figure 1b. All components of the AVR system are expressed by first-order transfer functions represented by the system gains and time constants $[4,56]$. A linear state-space form can be derived for AVR from the transfer functions of its components where the state vector " $x(t)=\left[\begin{array}{llll}V_{s}(t) & V_{t}(t) & V_{e}(t) & V_{a}(t)\end{array}\right]$ " as in Equations (1) and (2),

$$
\begin{gathered}
\dot{x}=A x+B u \\
y=c x
\end{gathered}
$$

where,

$$
\begin{gathered}
A=\left[\begin{array}{cccc}
-\frac{1}{T_{S}} & \frac{K_{S}}{T_{S}} & 0 & 0 \\
0 & -\frac{1}{T_{G}} & \frac{K_{G}}{T_{G}} & 0 \\
0 & 0 & -\frac{1}{T_{E}} & \frac{K_{E}}{T_{E_{1}}} \\
0 & 0 & 0 & -\frac{1}{T_{A}}
\end{array}\right], \\
B=\left[\begin{array}{llll}
0 & 0 & 0 & \frac{K_{A}}{T_{A}}
\end{array}\right]^{T}, \\
C=\left[\begin{array}{llll}
1 & 0 & 0 & 0
\end{array}\right],
\end{gathered}
$$

$V_{S}(t)$ The output voltage from the measuring device

$V_{t}(t)$ The terminal voltage of the generator

$V_{e}(t)$ The exciter voltage

$V_{a}(t)$ The amplifier voltage.

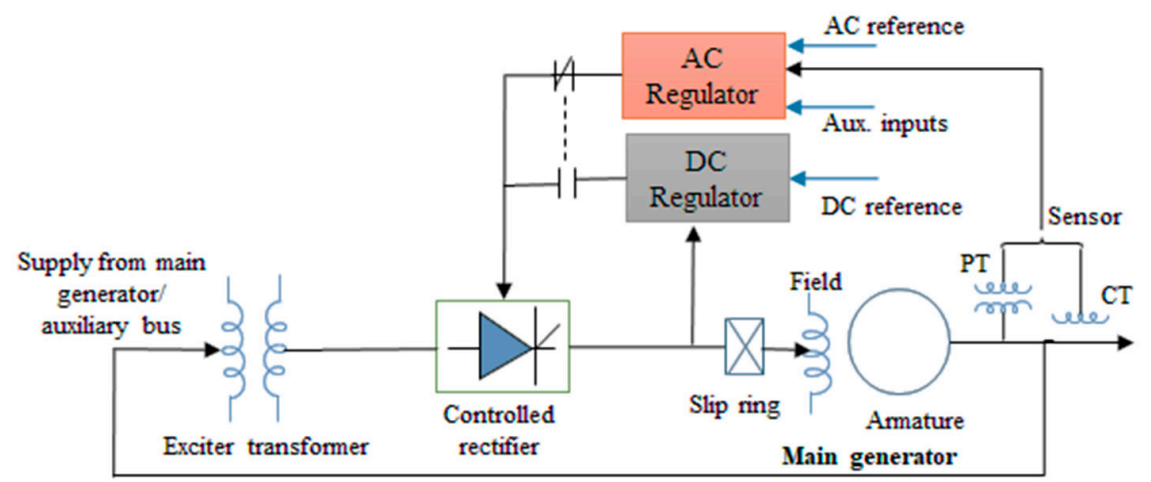

(a)

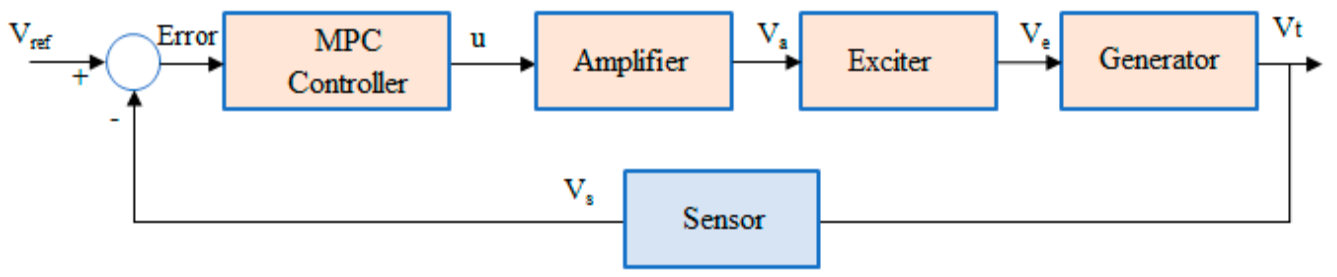

(b)

Figure 1. Scheme of AVR system (a) static excitation system and (b) structural diagram of AVR with the MPC controller.

\subsection{Formulation of $A V R$ for $M P C$}

The following discrete model in Equations (3) and (4) for the AVR system with sampling time 'Ts' is considered [57],

$$
\begin{gathered}
x(k+1)=A_{d} x(k)+B_{d} u(k) \\
y(k)=C_{d} x(k)
\end{gathered}
$$


An embedded integrator is combined with the above model in order to provide zero steady-state error as described in Equations (5) and (6),

$$
\begin{gathered}
x_{a}(k+1)=A_{a} x_{a}(k)+B_{a} \Delta u(k) \\
y(k)=C_{a} x_{a}(k)
\end{gathered}
$$

where,

$$
\begin{aligned}
& x_{a}(k)=\left[\begin{array}{ll}
\Delta x(k)^{T} & y(k)
\end{array}\right]^{T}, \\
& \Delta x(k)=x(k)-x(k-1), \\
& \Delta u(k)=u(k)-u(k-1) \text {, and } \\
& A_{a}=\left[\begin{array}{cc}
A_{d} & 0_{4 \times 1} \\
C_{d} A_{d} & 1
\end{array}\right], B_{a}=\left[\begin{array}{c}
B_{d} \\
C_{d} B_{d}
\end{array}\right], C_{a}=\left[\begin{array}{ll}
0_{4 \times 1}^{T} & 1
\end{array}\right]
\end{aligned}
$$

The MPC formulation utilizes the derived new model in Equations (5) and (6), named the augment model, to adjust the incremental control signal ' $\Delta U^{\prime}$ ' within a specific control horizon ' $C$ ' in order to predict the system outputs for a certain prediction horizon ' $P$ ' as described in Equation (7),

$$
Y=F x_{a}(k)+\Psi \Delta U
$$

where,

$$
\begin{gathered}
Y=[y(k+1), y(k+2), \ldots, y(k+P)]^{T} \\
\Delta U=[\Delta u(k), \Delta u(k+1) \ldots, \Delta u(k+C-1)]^{T}
\end{gathered}
$$

and

$$
\begin{gathered}
F=\left[\begin{array}{cccc}
C_{d} A_{d} & C_{d} A_{d}{ }^{2} & \ldots & C_{d} A_{d}{ }^{P}
\end{array}\right]^{T} \\
\Psi=\left[\begin{array}{cccc}
C_{a} B_{a} & 0 & \ldots & 0 \\
C_{a} A_{a} B_{a} & C_{a} B_{a} & \ldots & 0 \\
\vdots & \vdots & \ddots & \vdots \\
C_{a} A_{a}^{P-1} B_{a} & C_{a} A_{a}^{P-2} B_{a} & \ldots & C_{a} A_{a}^{P-C} B_{a}
\end{array}\right]
\end{gathered}
$$

\subsection{Obtaining the Control Law of MPC}

The target of the MPC is to track the reference terminal voltage " $V_{\text {ref }}$ " by obtaining the optimal control signal utilizing the following cost function in Equation (8),

$$
J=\left(R_{s}-Y\right)^{T} Q_{w}\left(R_{s}-Y\right)+\Delta U^{T} R_{w} \Delta U
$$

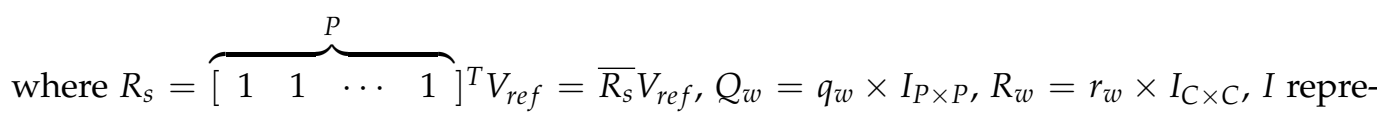
sents a unit diagonal matrix. The minimization of the error and control signal is governed by positive weights ' $q_{w}$ ' and ' $r_{w}$ ' respectively. By substituting Equation (7) for Equation (8), the cost function can be formulated in Equation (9),

$$
J=\left(R_{s}-F x_{a}(k)\right)^{T} Q_{w}\left(R_{s}-F x_{a}(k)\right)-2 \Delta U^{T} \Psi^{T} Q_{w}\left(R_{s}-F x_{a}(k)\right)+\Delta U^{T}\left(\Psi^{T} Q \Psi+R_{w}\right) \Delta U
$$

The optimal control solutions can be formulated by deriving the partial derivative of $J$ according to $\Delta U$ as described in Equation (10),

$$
\frac{\partial J}{\partial \Delta U}=-2 \Psi^{T} Q_{w}\left(R_{s}-F x_{a}(k)\right)+2\left(\Psi^{T} Q_{w} \Psi+R_{w}\right) \Delta U
$$

To get the optimal control action that can minimize $J$, we set the partial derivative of $J$ to zero as shown in Equation (11),

$$
\frac{\partial J}{\partial \Delta U}=0
$$


The optimal control law can be derived by solving Equations (10) and (11) together; then the optimal control law can be defined as shown in Equation (12),

$$
\Delta U=\left(\Psi^{T} Q_{w} \Psi+R_{w}\right)^{-1} \Psi^{T} Q_{w}\left(R_{s}-F x_{a}(k)\right)
$$

Then, the first control point in the predicted control vector is utilized to obtain the output, and the other control actions are ignored according to the receding horizon strategy as described in Equation (13),

$$
\begin{aligned}
& \Delta u(k)=\overbrace{\left[\begin{array}{llll}
1 & 0 & \cdots & 0
\end{array}\right]}^{C}\left(\Psi^{T} Q_{w} \Psi+R_{w}\right)^{-1} \Psi^{T} Q_{w}\left(\overline{R_{s}} V_{r e f}-F x_{a}(k)\right) \\
& =K_{y} V_{r e f}-K_{m p c} x_{a}(k)
\end{aligned}
$$

where,

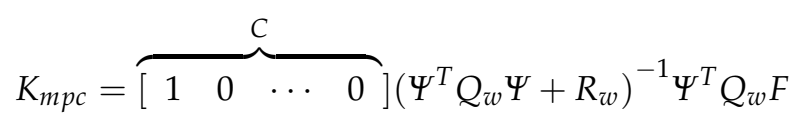

and

$$
K_{y}=\overbrace{\left[\begin{array}{llll}
1 & 0 & \cdots & 0
\end{array}\right]}^{C}\left(\Psi^{T} Q_{w} \Psi+R_{w}\right)^{-1} \Psi^{T} Q_{w} \overline{R_{s}}
$$

Then, the closed-loop form system can be derived by substituting $\Delta U(k)$ from Equation (13) in the augmented model of Equation (5) as shown in Equation (14),

$$
\begin{aligned}
x_{a}(k+1) & =A_{a} x_{a}(k)+B_{a}\left(K_{y} V_{r e f}-K_{m p c} x_{a}(k)\right) \\
& =\left(A_{a}-B_{a} K_{m p c}\right) x_{a}(k)+B_{a} K_{y} V_{r e f}
\end{aligned}
$$

The eigenvalues of the closed-loop form in Equation (14) can be obtained by solving the closed-loop characteristic polynomial in Equation (15),

$$
P=\operatorname{det}\left[\lambda I-\left(A_{a}-B_{a} K_{m p c}\right)\right]=0
$$

\section{Robust MPC Formulation}

The uncertainty of the AVR parameters, such as time constants and gains, stand for the main issue against the MPC to provide good performance. In this paper, all nominal values ' $K_{A}=10, T_{A}=0.1 s, K_{E}=1, T_{E}=0.4 s, K_{G}=1, T_{G}=1 s, K_{S}=1$, and $T_{S}=0.01 s^{\prime}[51-55]$ of the system time constants and gains are assumed to be uncertain around its nominal value ' $N$ ' by an uncertainty radius ' $\delta_{N}=10 \%$ ' within the interval $\left[\begin{array}{ll}\left(1-\delta_{N}\right) N^{\circ} & \left(1+\delta_{N}\right) N^{\circ}\end{array}\right]$. Thus, the state matrix 'Aa' of the AVR system is a perturbed matrix because it is expressed by the system's time constants and gains. Thus, this uncertainty problem must be taken into account by adjusting the MPC gains ' $K_{m p c}$ '. To handle this uncertainty issue, we define the closed-loop characteristic polynomial in Equation (15) as defined in Equation (16),

$$
P=\operatorname{det}\left[\lambda I-\left(A_{a}-B_{a} K_{m p c}\right)\right]=b_{5} \lambda^{5}+b_{4} \lambda^{4}+b_{3} \lambda^{3}+b_{2} \lambda^{2}+b_{1} \lambda+b_{0}=0
$$

where $P$ is the closed-loop characteristic polynomial of the AVR system. However, the uncertainty of the system time constants and gains will generate a family of polynomials including the nominal polynomial. In addition, the parameters $\left(b_{0}, \ldots, b_{5}\right)$ of the polynomial ' $P$ ' will have bounded uncertainty as, $b_{i} \in\left[\begin{array}{cc}\alpha_{i} & \sigma_{i}\end{array}\right], i=0, \cdots, 5$. To derive the constraints that can ensure the stability of the generated family of plants from the perturbed polynomial ' $P$ ', we substitute $\lambda=j \omega$ in Equation (16) and assume $\eta=\omega^{2}$ then the perturbed polynomial ' $P$ ' can be defined in Equation (17),

$$
P(j \eta)=H(\eta)+j \omega Q(\eta)
$$


where the even terms of $P(j \eta)$ are included in $H(\eta)$ as defined in Equation (18) and the odd ones are included in $Q(\eta)$ as defined in Equation (19).

$$
\begin{aligned}
& H(\eta)=b_{0}-b_{2} \eta+b_{4} \eta^{2} \\
& Q(\eta)=b_{1}-b_{3} \eta+b_{5} \eta^{2}
\end{aligned}
$$

Considering the uncertainty interval ' $b_{i} \in\left[\begin{array}{cc}\alpha_{i} & \sigma_{i}\end{array}\right], i=0, \cdots, 5^{\prime}$ :

$$
\begin{aligned}
& \bar{H}(\eta)=\rho_{0}-\alpha_{2} \eta+\rho_{4} \eta^{2} \\
& H(\eta)=\alpha_{0}-\rho_{2} \eta+\alpha_{4} \eta^{2}
\end{aligned}
$$

and

$$
\begin{aligned}
& \bar{Q}(\eta)=\rho_{1}-\alpha_{3} \eta+\rho_{5} \eta^{2} \\
& Q(\eta)=\alpha_{1}-\rho_{3} \eta+\alpha_{5} \eta^{2}
\end{aligned}
$$

The frequency bands of $H(\eta)$ are defined by listing the roots of $\bar{H}(\eta)$ in Equation (20) and $H(\eta)$ in Equation (21) ascending. Likewise, the frequency bands of $Q(\eta)$ are given by listing the roots of $\bar{Q}(\eta)$ in Equation (22) and $Q(\eta)$ in Equation (23) in ascending as illustrated in Figure 2. The following lemmas describe the properties of the frequency bands.

- Roots of $\bar{H}(\eta), H(\eta)$

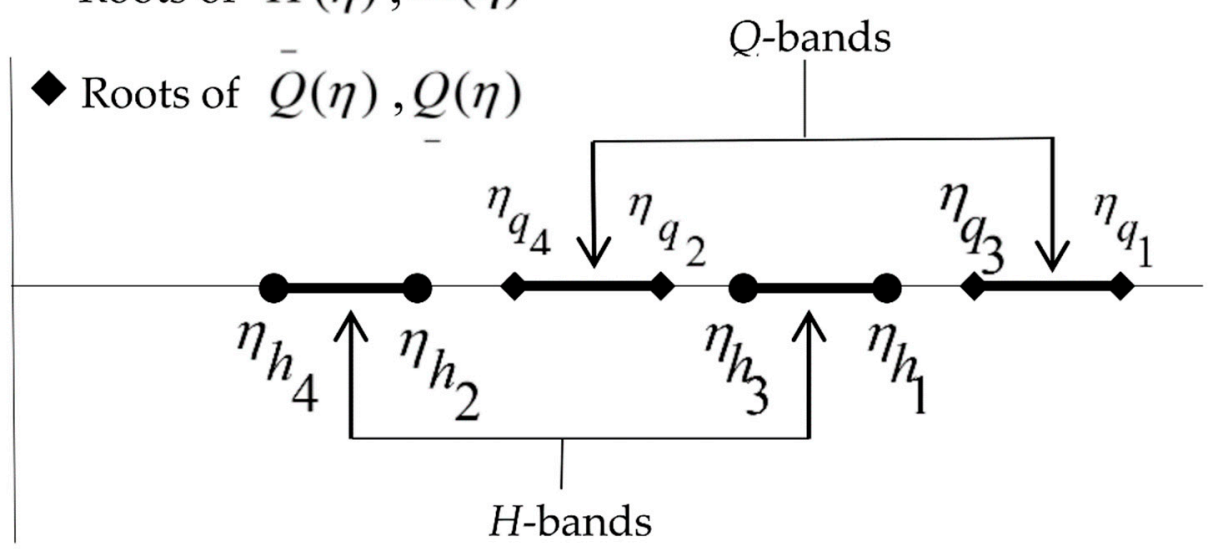

Figure 2. The alternation schematic of the frequency bands.

Lemma 1. The polynomial ' $P$ ' is stable if the roots of $\bar{H}(\eta), H(\eta), \bar{Q}(\eta)$, and $Q(\eta)$ are positive and real.

Lemma 2. The frequency bands of ' $H$ ' and ' $Q$ ' are continuous and confined by the roots of the interval polynomials $\bar{H}(\eta), H(\eta), \bar{Q}(\eta)$, and $Q(\eta)$ for ' $H$ ' and ' $Q$ ' frequency bands for continuous perturbations $\alpha_{i} \leq b_{i} \leq \rho_{i}$.

The stability constraints for the perturbed polynomial are defined by the following theorem.

Theorem 1. The polynomial ' $P$ ' that has uncertainty factors is stable for interval $\alpha_{i} \leq b_{i} \leq \rho_{i}$ if the frequency bands of ' $H$ ' and ' $Q$ ' are alternate without overlapping. These stability constraints of the perturbed polynomial ' $P$ ' of the AVR system that ensure the alternating and non-overlapping for the frequency bands are concluded as follows as defined in Equations (24)-(26), 


$$
\begin{aligned}
& \min \left(\eta_{q_{1}}, \eta_{q_{3}}\right)>\max \left(\eta_{h_{1}}, \eta_{h_{3}}\right) \\
& \min \left(\eta_{h_{1}}, \eta_{h_{3}}\right)>\max \left(\eta_{q_{2}}, \eta_{q_{4}}\right) \\
& \min \left(\eta_{q_{2}}, \eta_{q_{4}}\right)>\max \left(\eta_{h_{2}}, \eta_{h_{4}}\right)
\end{aligned}
$$

Proof. The frequency-domain constraints in Equations (24)-(26) that confirm the stability of the perturbed polynomial are a part of Kharitonov's theorem and were demonstrated by Argoun $[58,59]$. Moreover, Hermite-Biehler theorem derived the alternate condition [60].

\section{Arithmetic Optimization Algorithm Overview}

Arithmetic optimization algorithm (AOA) is a new meta-heuristic approach that uses the distribution behavior of four basic arithmetic processes such as addition, subtraction, multiplication, and division in solving optimization processes [43]. The AOA can be summarized as follows: firstly, the search phase is required to be chosen by using the math optimizer accelerated (MOA) function as shown in Equation (27),

$$
F_{M O A}\left(I_{c}\right)=A_{\min }+I_{c} \times\left(\frac{A_{\max }-A_{\min }}{I_{M}}\right)
$$

where $F_{M O A}\left(I_{C}\right)$ describes the mean value of the MOA function calculated at the current iteration $I_{c} . I_{M}$ is the total iterations of the MOA function. $A_{\min }$ and $A_{\max }$ represent the minimum and maximum values of the MOA function. Based on the calculated values of $F_{M O A}\left(I_{c}\right)$, it can be decided whether the exploration or exploitation phase of the AOA is selected.

\subsection{Exploration Stage}

The exploration stage is used to randomly explore the search region to determine a better solution using two methods: multiplication search strategy and the division search strategy. Equation (28) represents the exploration operator of the AOA. It is assumed that $\mathrm{r} 1$ is a random number with the condition of $r_{1}>F_{M O A}$. The modeled behaviors of the multiplication or division operators for the position updating process are shown in Equation (28),

$$
x_{i, j}\left(I_{c}+1\right)=\left\{\begin{array}{c}
\operatorname{Best}\left(x_{j}\right) \div(M+\varepsilon) \times\left[\left(U_{j}-L_{j}\right) \times \mu+L_{j}\right], r_{2}<0.5 \\
\operatorname{Best}\left(x_{j}\right) \times M \times\left[\left(U_{j}-L_{j}\right) \times \mu+L_{j}\right], \text { otherwise }
\end{array}\right.
$$

where $x_{i, j}\left(I_{c}+1\right)$ presents the $i$ th solution in the next iteration. Best $\left(x_{j}\right)$ is the best solution that can be obtained at the $j$ th position. $r_{2}$ stands for a random value. $U_{j}$ and $L_{j}$ denote the upper and lower bound values at the $j$ th location, respectively. $\varepsilon$ performs the small integer value and $\mu$ is a control coefficient for optimal search. The math optimizer probability value ' $M$ ' at the current iteration can be calculated using Equation (29),

$$
M\left(I_{C}\right)=1-\left(\frac{I_{C}^{1 / \alpha}}{I_{M}^{1 / \alpha}}\right)
$$

where $\alpha$ presents a sensitive coefficient that can be determined experimentally.

\subsection{Exploitation Stage}

The exploitation stage utilizes addition and subtraction operators to define a better solution under the condition of $r_{1} \leq F_{M O A}$. The searching strategy based on the exploitation phase is formulated by Equation (30),

$$
x_{i, j}\left(I_{c}+1\right)=\left\{\begin{array}{c}
\operatorname{Best}\left(x_{j}\right)-M \times\left[\left(U_{j}-L_{j}\right) \times \mu+L_{j}\right], r_{3}<0.5 \\
\operatorname{Best}\left(x_{j}\right)+M \times\left[\left(U_{j}-L_{j}\right) \times \mu+L_{j}\right], \text { otherwise }
\end{array}\right.
$$


The structure diagram of the AOA is detailed in Figure 3.

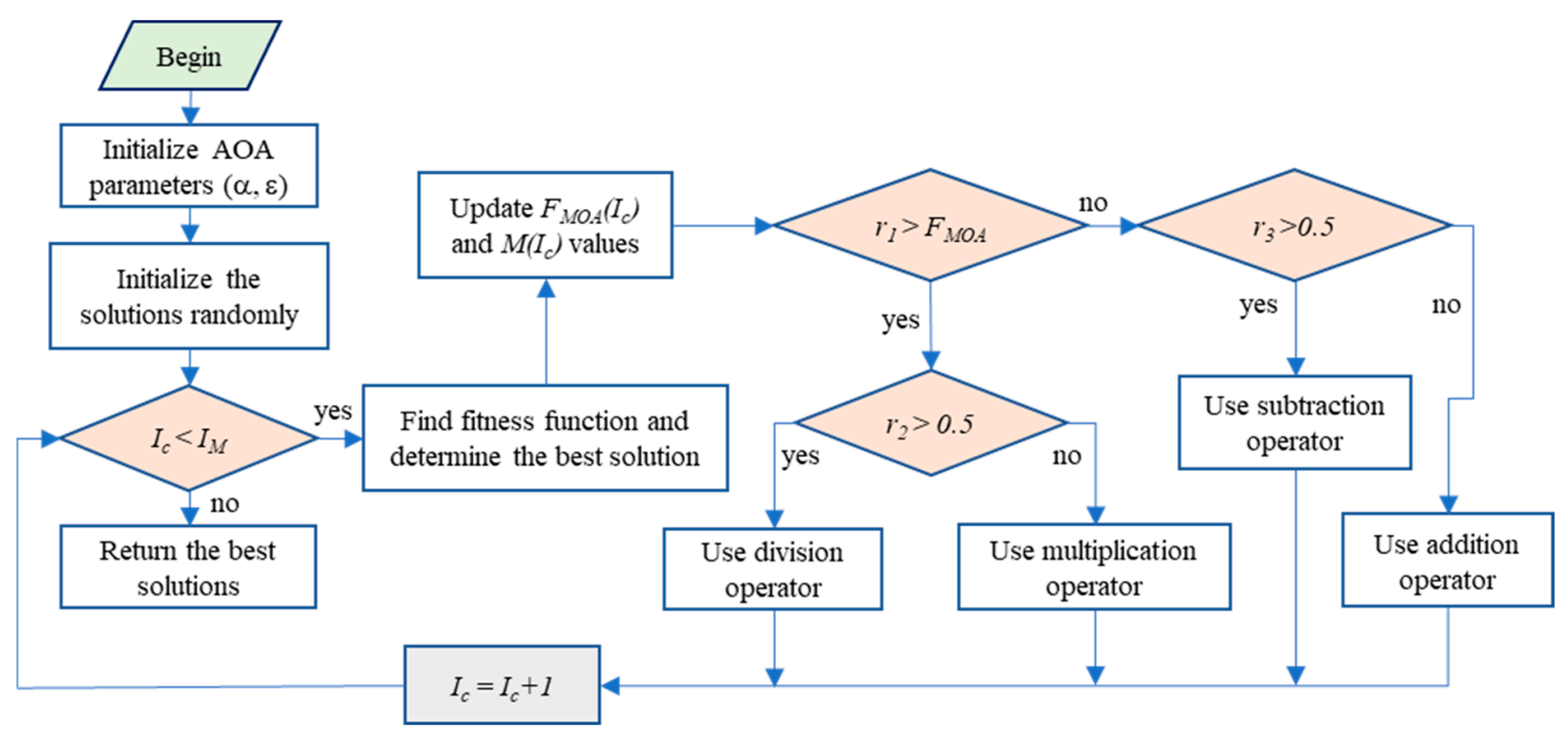

Figure 3. The structure diagram of the AOA.

\section{Results and Discussion}

In this part, the suggested AOA is dedicated to design a robust MPC that handles the frequency domain constraints derived from Hermite-Biehler theorem. The proposed AOA requires few adjustable parameters that enhance the performance of the AVR with a fast convergence rate and overcome the trapping in local optima issue instead of other algorithms. Then, the effectiveness and robustness of the suggested technique are validated by comparing the designed robust MPC based on AOA with ABC [51], NSGA-II [52], MOE [53], FSA [54], and multi-objective PID [55]. The tuning of the MPC parameters such as the sample time ' $T s^{\prime}$ ', the control horizon ' $C$ ', the prediction horizon ' $P$ ', the control weight factor ' $r w$ ', and the output weight factor ' $\mathrm{qw}^{\text {' }}$ are performed by AOA based on a developed fitness function that can confirm decrease of the voltage maximum overshoot and the response settling time simultaneously as well as achieving the frequency domain constraints. The developed fitness function is named figure of demerit $(F o D)$ and it is formulated as defined in Equation (31),

$$
\text { FoD }=\left(1-e^{-\phi}\right)\left(M_{o}+e_{S S}\right)+e^{-\phi} \times\left(t_{s}-t_{r}\right)
$$

The frequency domain constraints are,

$$
\begin{aligned}
& \min \left(\alpha_{q_{1}}, \alpha_{q_{3}}\right)>\max \left(\alpha_{h_{1}}, \alpha_{h_{3}}\right) \\
& \min \left(\alpha_{h_{1}}, \alpha_{h_{3}}\right)>\max \left(\alpha_{q_{2}}, \alpha_{q_{4}}\right) \\
& \min \left(\alpha_{q_{2}}, \alpha_{q_{4}}\right)>\max \left(\alpha_{h_{2}}, \alpha_{h_{4}}\right)
\end{aligned}
$$

where $M_{o}$ represents the terminal voltage maximum overshoot, while $e_{s s}$ stands for the response steady-state error, ts is the response settling time, and tr is the response rise time. $\phi$ is a weighting factor utilized to equalize the decreasing process of the voltage maximum overshoot and the response settling time during the optimization process. When $\phi>0.7$, the AOA focuses on minimizing the voltage maximum overshoot. While the optimization algorithm focuses on minimizing the response settling time at $\phi<0.7$. In this paper, $\phi$ is chosen equal to 0.7 because at $\phi=0.7$, the two parts " $\left(1-e^{-\phi}\right)$ and $e^{-\phi "}$ of the fitness function are equal " $\left(1-e^{-\phi}\right)=e^{-\phi} \approx 0.5^{\prime \prime}$ and the optimization algorithm can equalize the decreasing process of the voltage maximum overshoot and the response settling time 
during the optimization simultaneously. The utilized parameters of the AOA to perform the tuning process are "population size $=100$ and iteration number $=50$ ". The optimization process is carried out on MATLAB R2019b by personal computer intel CORE i7 and has $8 \mathrm{~g}$ RAM. The following pseudo-code in Algorithm 1 summarizes the main steps to design the robust MPC based on AOA.

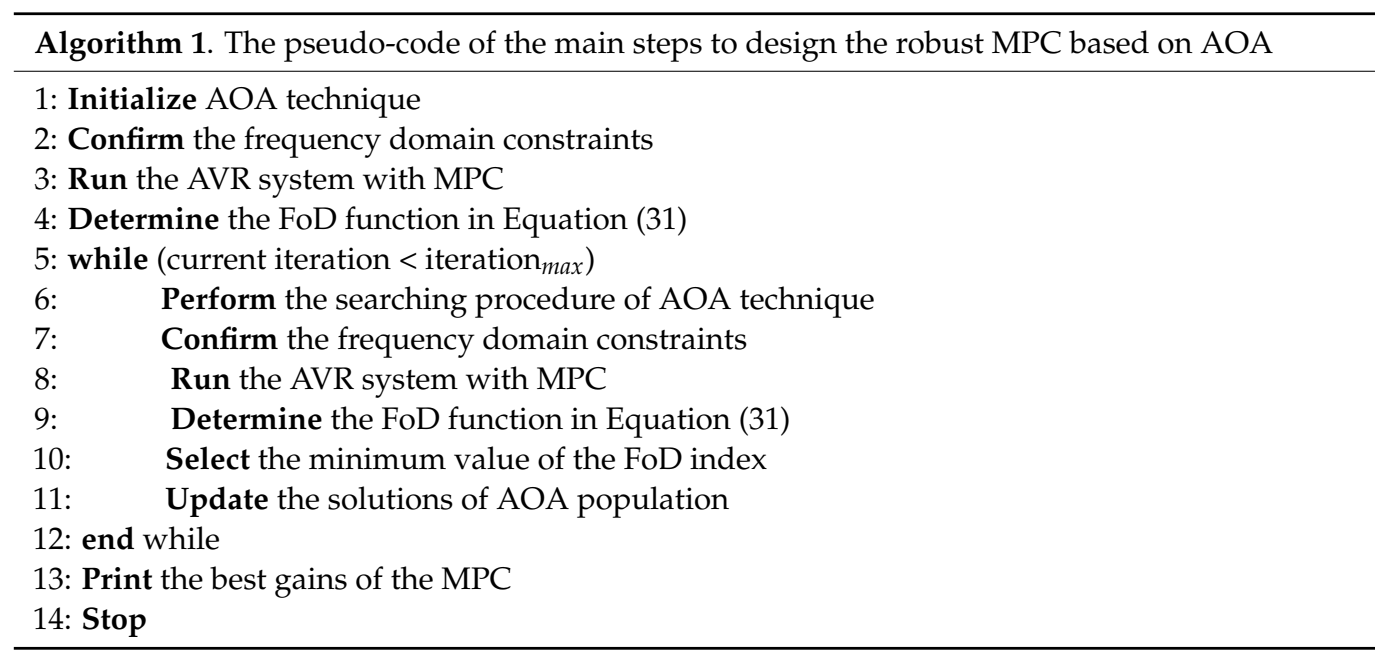

The parameters of the designed robust MPC are based on AOA, the parameters of other controllers, and the corresponding values of the FoD function are listed in Table 1. Figure 4 presents the FoD values in a bar chart based on the proposed AOA-based robust MPC and other techniques. Table 1 and Figure 4 show that the proposed AOA-based robust MPC has the minimum FoD value compared with other methods in the literature. The eigenvalue locations of the AVR based on the proposed AOA- robust MPC are presented in Figure 5. It is shown from this figure that the proposed AOA-robust MPC can stabilize the AVR system and make all eigenvalue locations inside the unit circle. Furthermore, Figure 6 shows the frequency domain bands based on the proposed AOA- robust MPC. The frequency-domain bands alternate and do not overlap, as shown in Figure 6, which proves the robustness of the designed MPC against the AVR parameters uncertainty.

Table 1. Controller parameters based on each algorithm and the corresponding objective value.

\begin{tabular}{ccc}
\hline Controller Type & Controller Gains & FoD Value \\
\hline ABC-based PID & $\mathrm{k}_{\mathrm{p}}=1.6524, \mathrm{k}_{\mathrm{i}}=0.4083, \mathrm{k}_{\mathrm{d}}=0.3654$ & 1.5844 \\
\hline NSGA-II-based PID & $\mathrm{k}_{\mathrm{p}}=2.7666, \mathrm{k}_{\mathrm{i}}=0.4991, \mathrm{k}_{\mathrm{d}}=0.5008$ & 1.1335 \\
\hline MOEO-based PID & $\mathrm{k}_{\mathrm{p}}=0.8503, \mathrm{k}_{\mathrm{i}}=0.7473, \mathrm{k}_{\mathrm{d}}=0.3874$ & 0.3895 \\
\hline FSA-based PID & $\mathrm{k}_{\mathrm{p}}=0.6450, \mathrm{k}_{\mathrm{i}}=0.4730, \mathrm{k}_{\mathrm{d}}=0.2550$ & 0.0805 \\
\hline Multi-objective PID & $\mathrm{k}_{\mathrm{p}}=0.612, \mathrm{k}_{\mathrm{i}}=0.463, \mathrm{k}_{\mathrm{d}}=0.2$ & 0.0878 \\
\hline Proposed AOA based robust MPC & $\mathrm{T}_{\mathrm{s}}=0.012, \mathrm{C}=4, \mathrm{P}=30, \mathrm{r}_{\mathrm{w}}=0.01, \mathrm{q}_{\mathrm{w}}=1$ & 0.0574 \\
\hline
\end{tabular}

Several comparisons between the proposed AOA- robust MPC and other techniques are done to eliminate the performance and the robustness of the suggested strategy including; unit step reference for the terminal voltage, different references for the terminal voltage, and controller gains and system parameters uncertainty. Figures 7 and 8 show the voltage response based on the proposed AOA-based robust MPC and each technique in case of unit step reference for the terminal voltage at the nominal AVR parameters. Figure 9 shows the control effort of the proposed AOA-based robust MPC and each technique. Table 2 records the damping characteristics and the maximum control signal due to the proposed AOA-based robust MPC and each technique. Figures 10-12 show the settling time, the voltage maximum overshoot, and the maximum control signal respectively, using the 
proposed AOA-based robust MPC and each technique. It is concluded from Figures 7-12 and Table 2 that the suggested AOA-based robust MPC can provide the best damping response with less control effort compared with other techniques. Furthermore, different references for the terminal voltage are applied, as is clear in Figure 13, to emphasize the capability of the suggested AOA-based robust MPC against voltage variations. The voltage response based on the proposed AOA-based robust MPC and each technique in case of different step references are depicted in Figures 14 and 15. It is concluded from these figures that the suggested AOA-based robust MPC still provides the best damped voltage response compared with other techniques against reference variations. In Figures 16 and 17, simultaneous uncertainties of $\pm 10 \%$ in AVR time constants and perturbation of $\pm 10 \%$ of controller parameters are handled respectively. Figures 16 and 17 show that the proposed AOA-based robust MPC has a negligible change in the voltage response that proves the robustness of the designed MPC against the parameters' uncertainty.

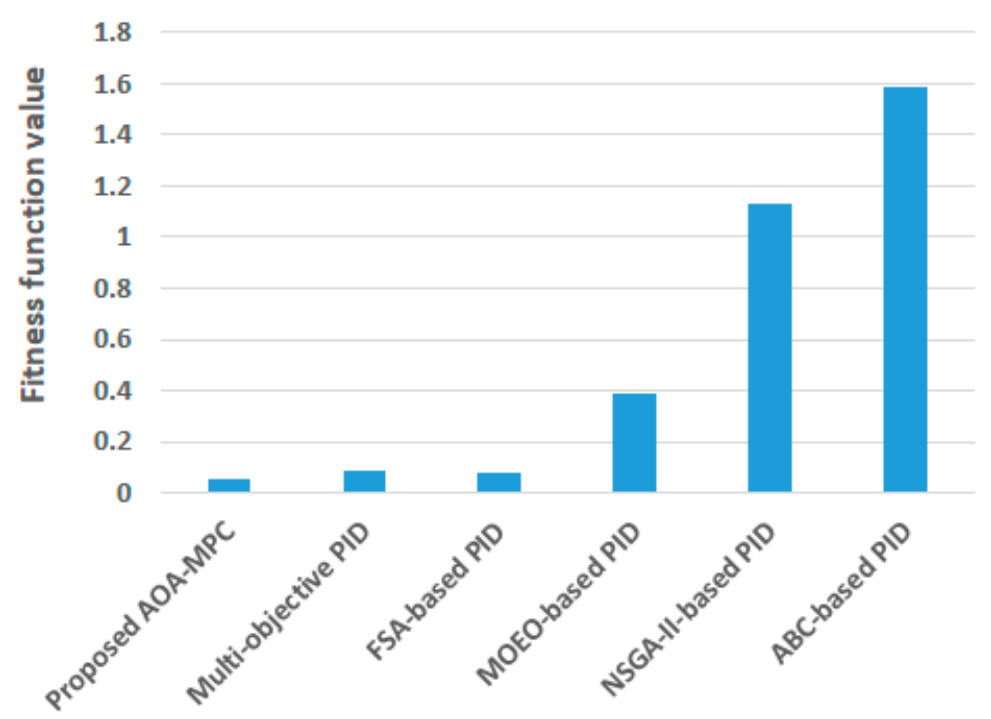

Figure 4. The fitness function values based on the proposed AOA-based robust MPC and other techniques.

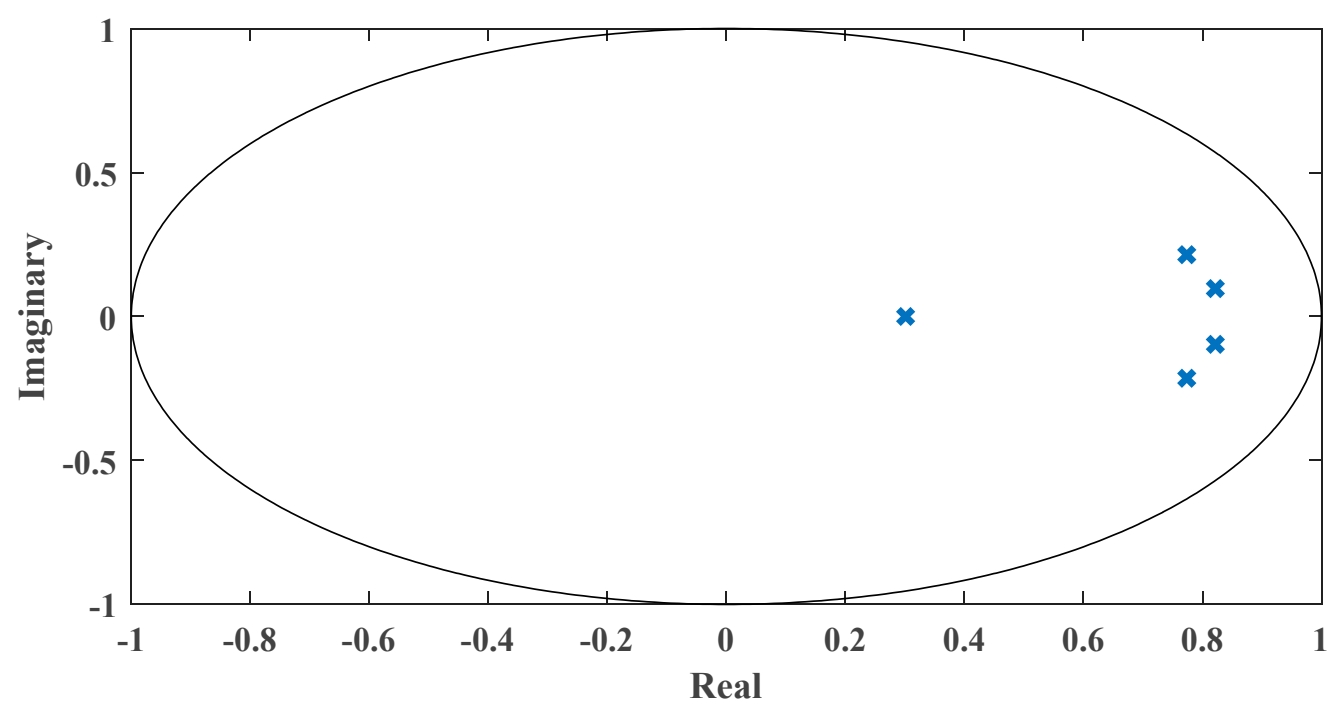

Figure 5. The eigenvalue locations of the AVR based on the proposed AOA- robust MPC. 
Roots of $\mathrm{Q}(\alpha)_{\max }, \mathrm{Q}(\alpha)_{\min }$

Roots of $\mathrm{H}(\alpha)_{\max }, \mathrm{H}(\alpha)_{\min } \quad$ Q-bands

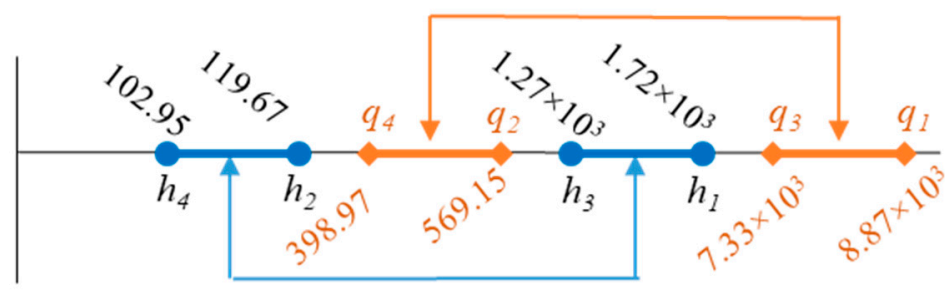

H-bands

Figure 6. The frequency domain bands based on the proposed AOA- robust MPC.
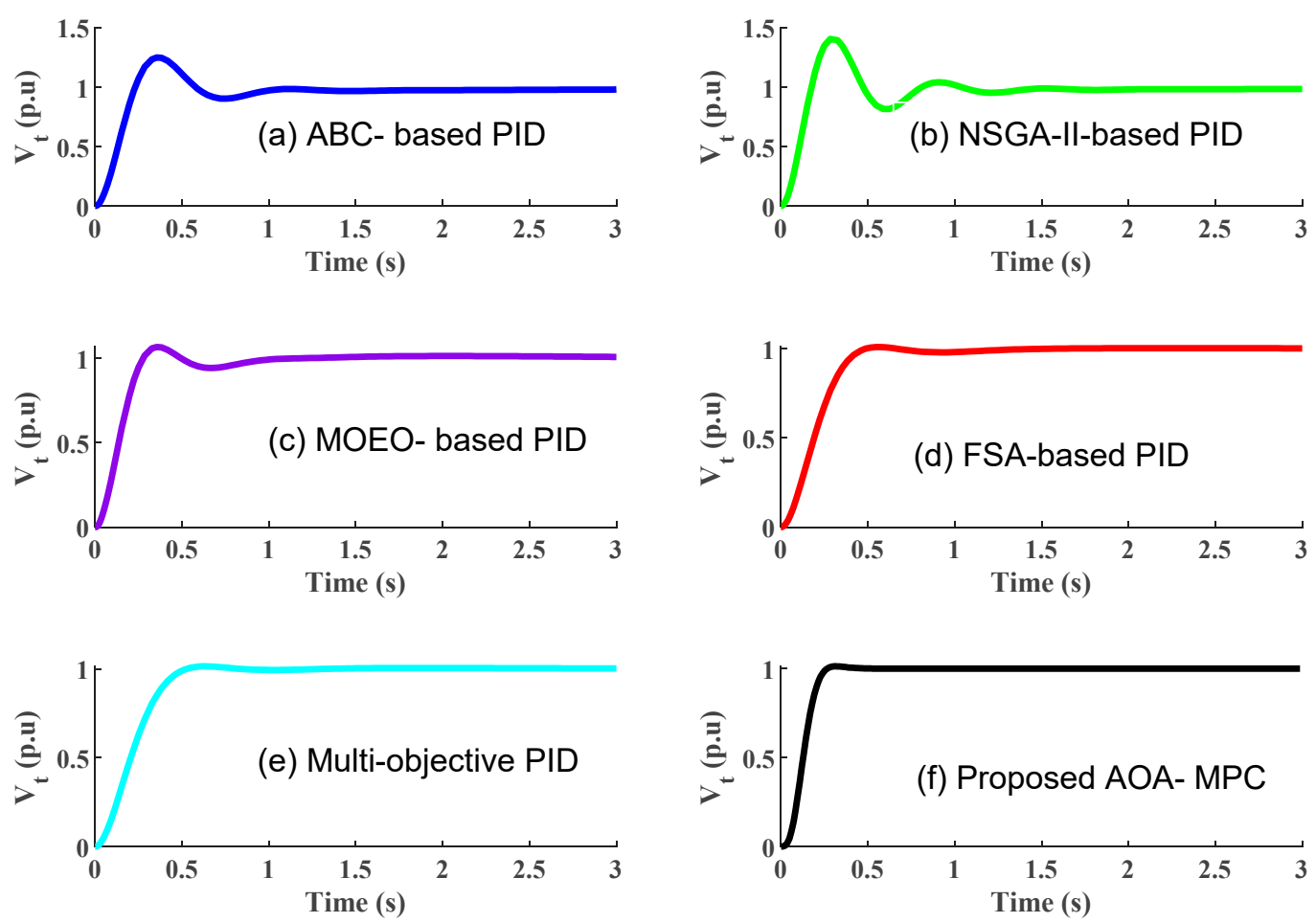

Figure 7. The terminal voltage based on the proposed AOA-based robust MPC and each technique in case of unit step reference.

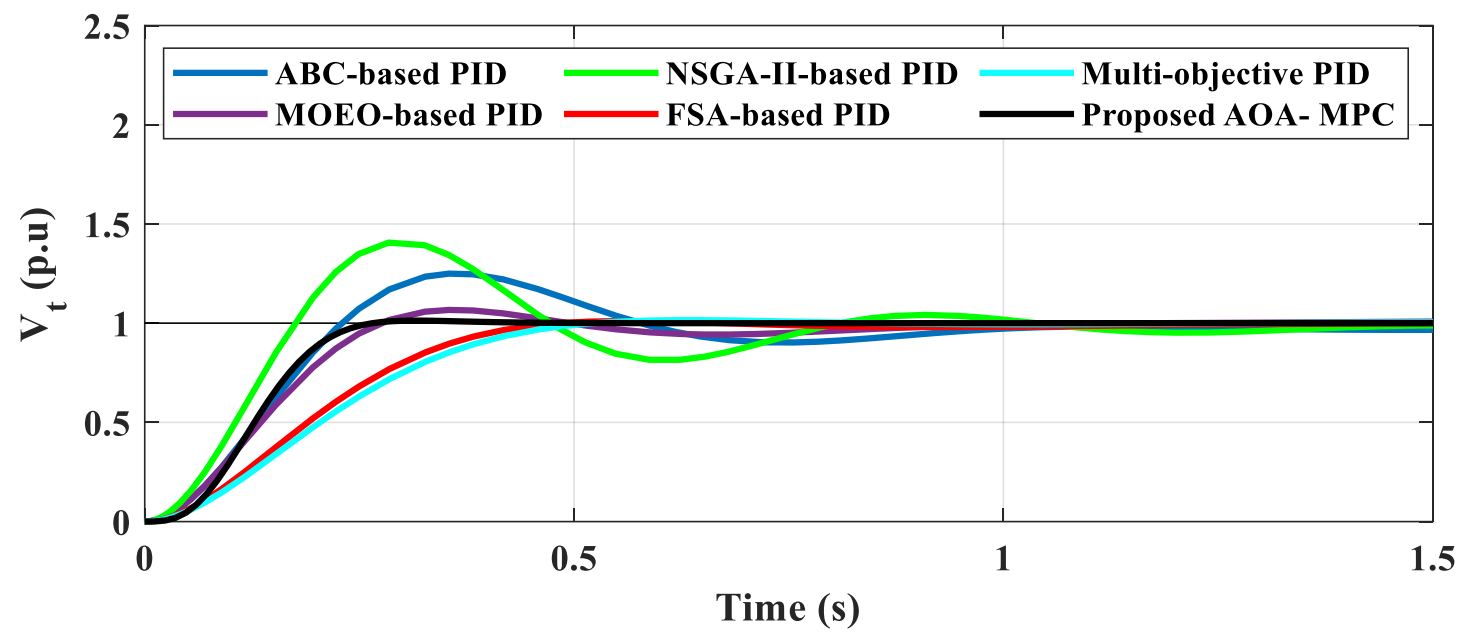

Figure 8. Combination of voltage responses based on the proposed AOA-based robust MPC and each technique in case of unit step reference. 


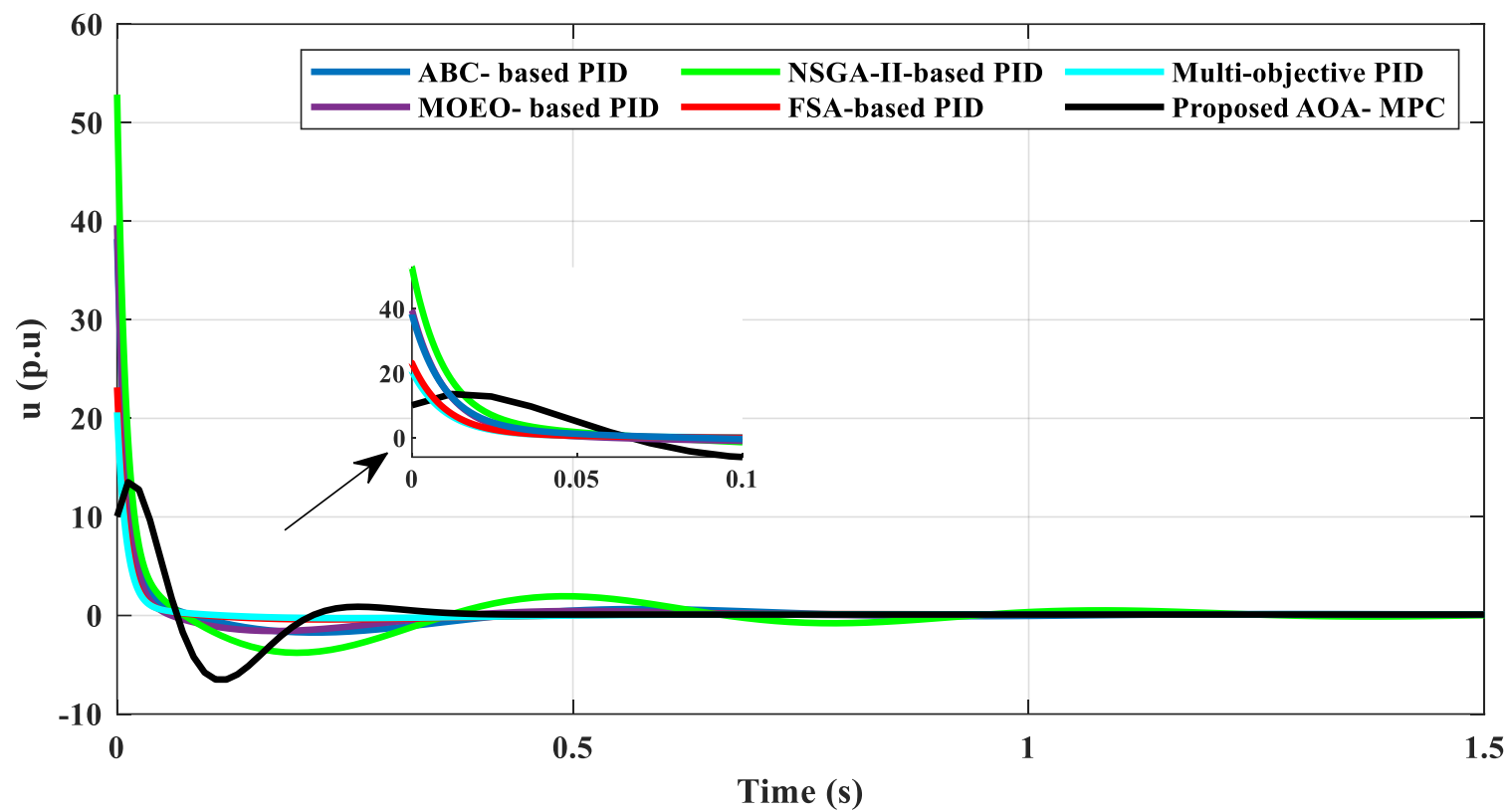

Figure 9. The control signals using the proposed AOA-based robust MPC and each technique.

Table 2. The voltage maximum overshoot, settling time, and maximum control signal.

\begin{tabular}{cccc}
\hline Controller Type & $\mathbf{t}_{\mathbf{s}}(\mathbf{s})$ & $\mathbf{M}_{\mathbf{o}} \mathbf{( \% )}$ & $\mathbf{u}_{\mathbf{m a x}}(\mathbf{p} \cdot \mathbf{u})$ \\
\hline ABC-based PID & 3.0939 & 24.9592 & 38.19 \\
\hline NSGA-II-based PID & 1.9894 & 40.5778 & 52.85 \\
\hline MOEO-based PID & 0.8995 & 6.6678 & 39.59 \\
\hline FSA-based PID & 0.4417 & 1.0460 & 23.14 \\
\hline Multi-objective PID & 0.4783 & 1.5164 & 20.61 \\
\hline Proposed AOA based robust MPC & 0.2444 & 1.2862 & 13.52 \\
\hline
\end{tabular}

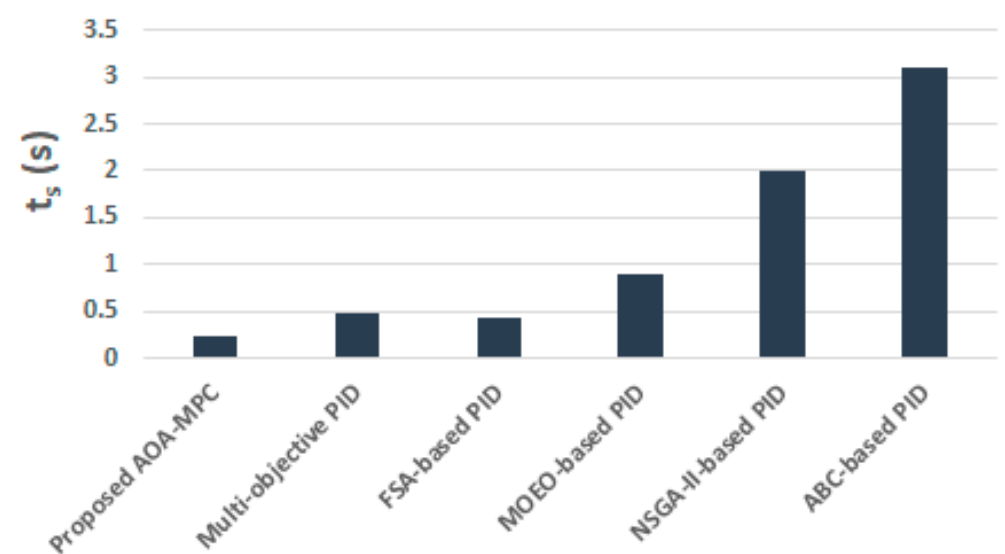

Figure 10. The settling times of the voltage response using the proposed AOA-based robust MPC and each technique. 


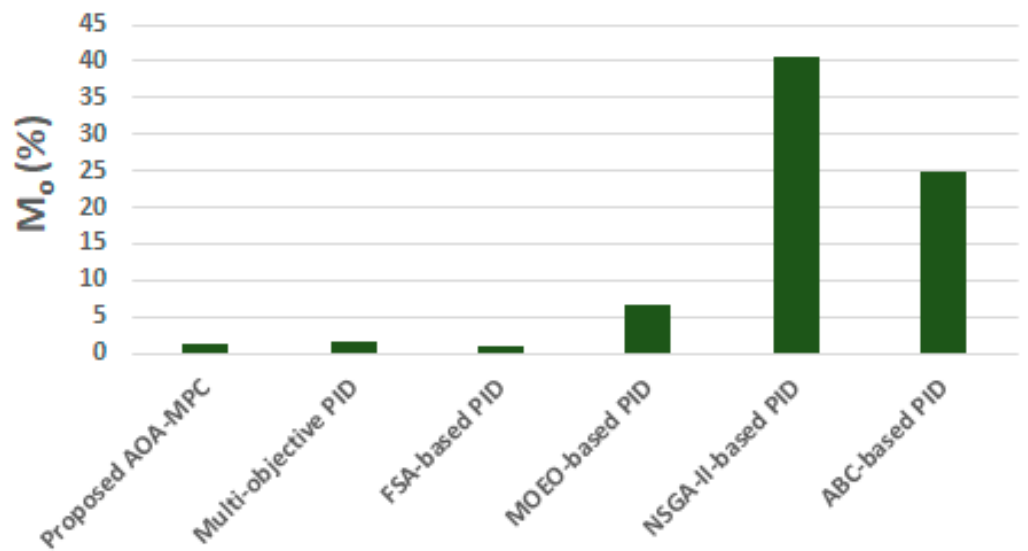

Figure 11. The maximum overshoot of the voltage response using the proposed AOA-based robust MPC and each technique.

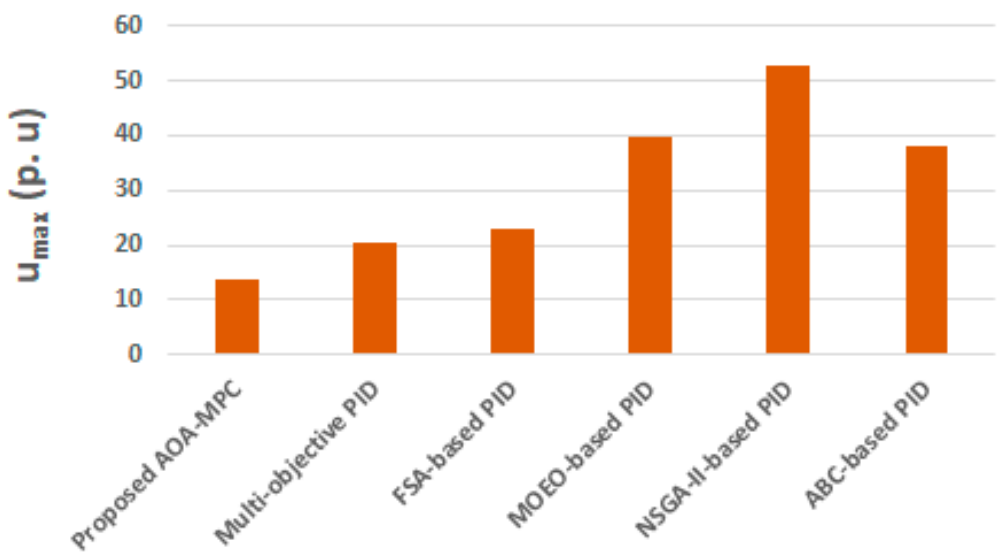

Figure 12. The maximum control signal using the proposed AOA-based robust MPC and each technique.

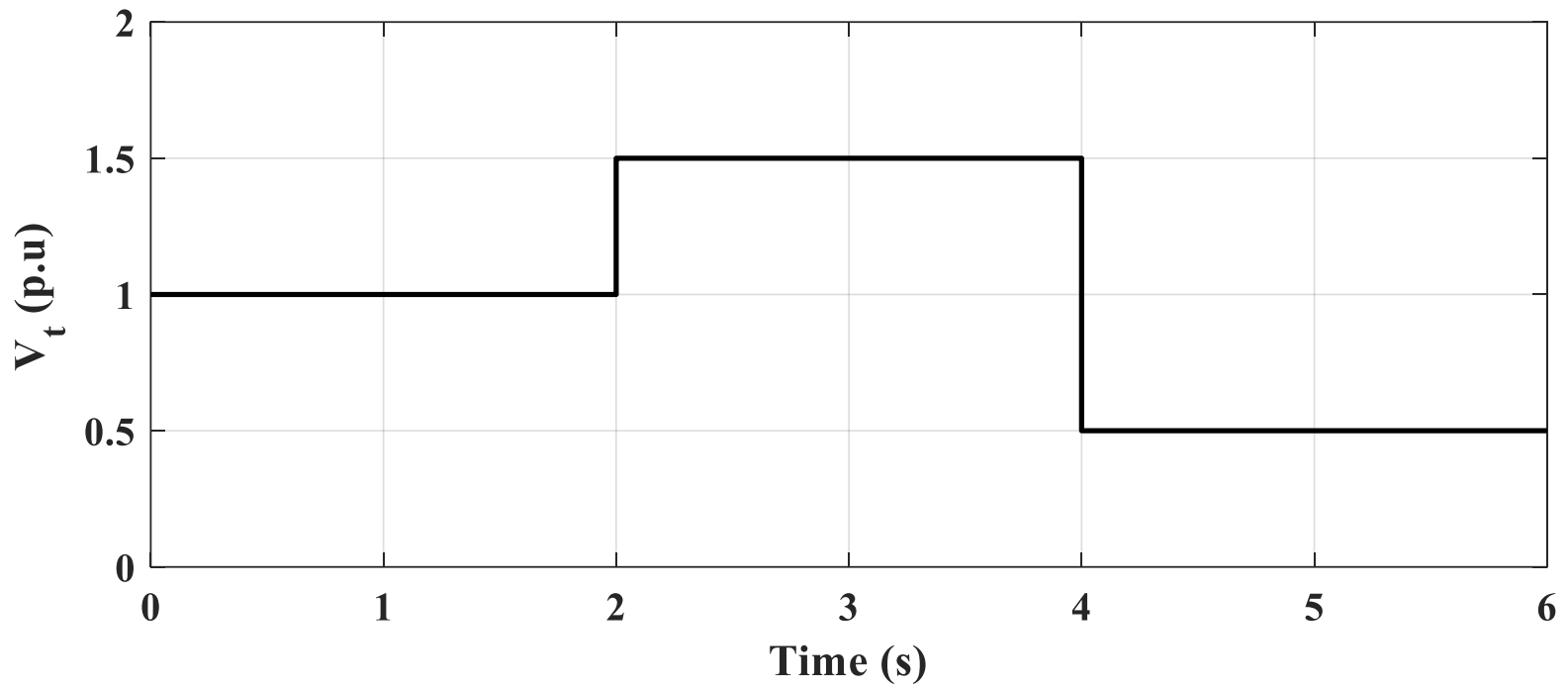

Figure 13. Voltage variations profile in case of different reference steps. 

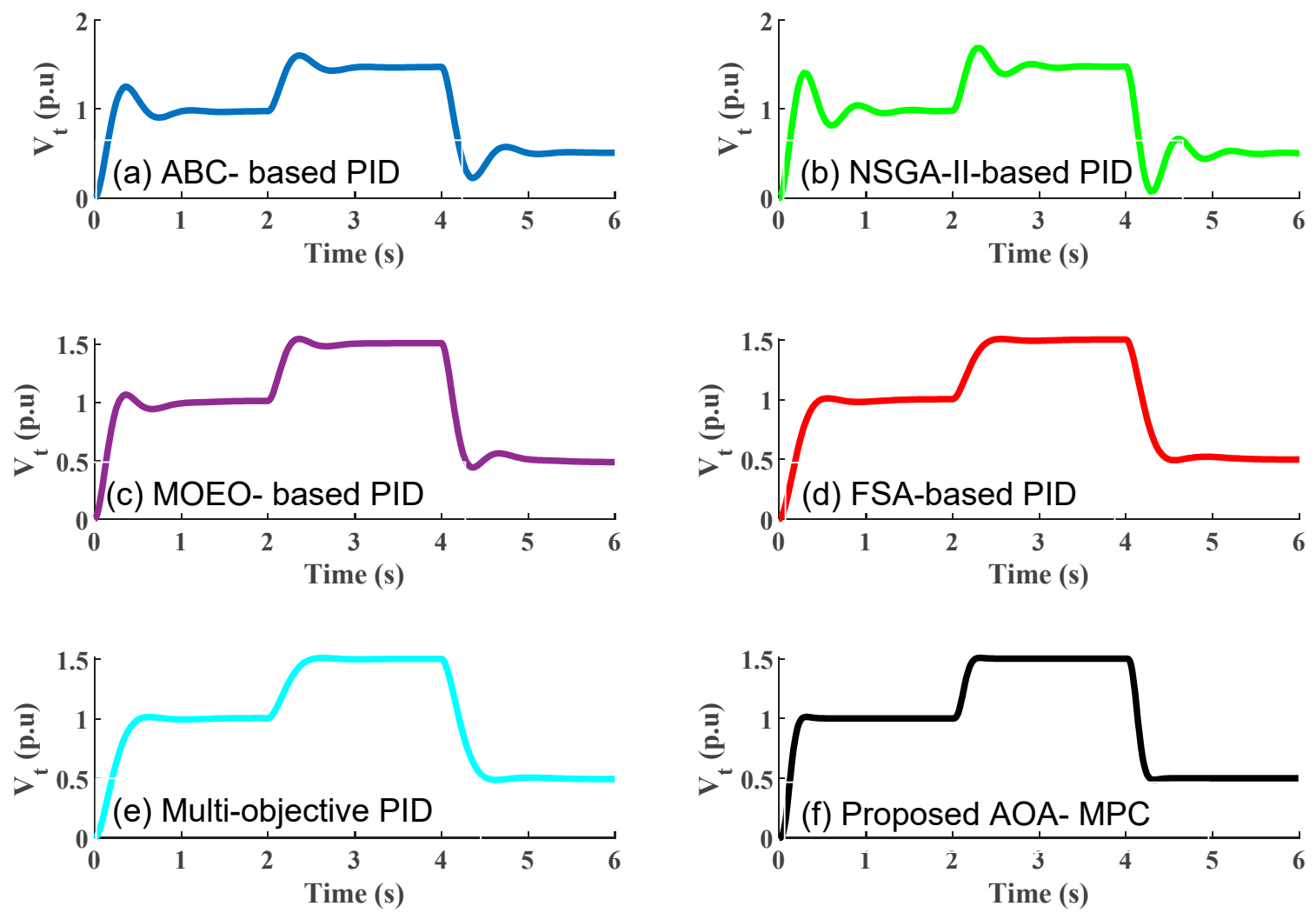

Figure 14. The terminal voltage based on the proposed AOA-based robust MPC and each technique in case of different step references.

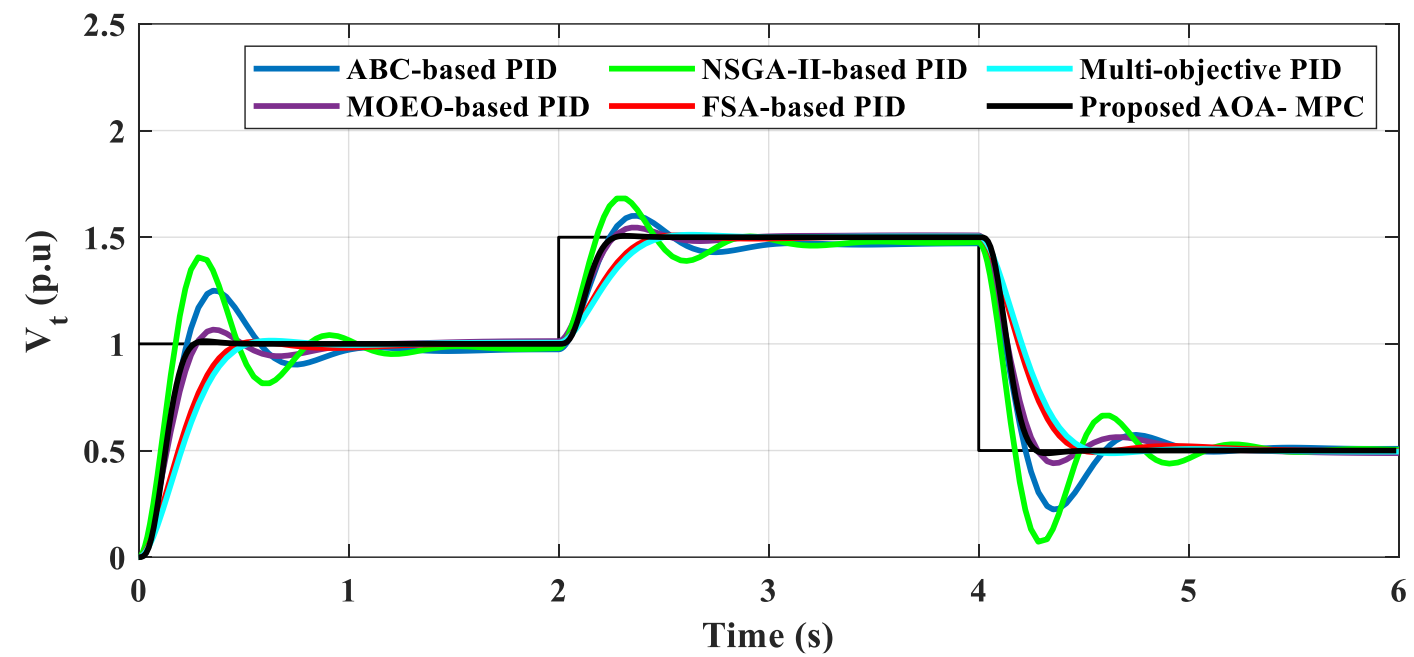

Figure 15. Combination of voltage responses based on the proposed AOA-based robust MPC and each technique in case of different step references. 

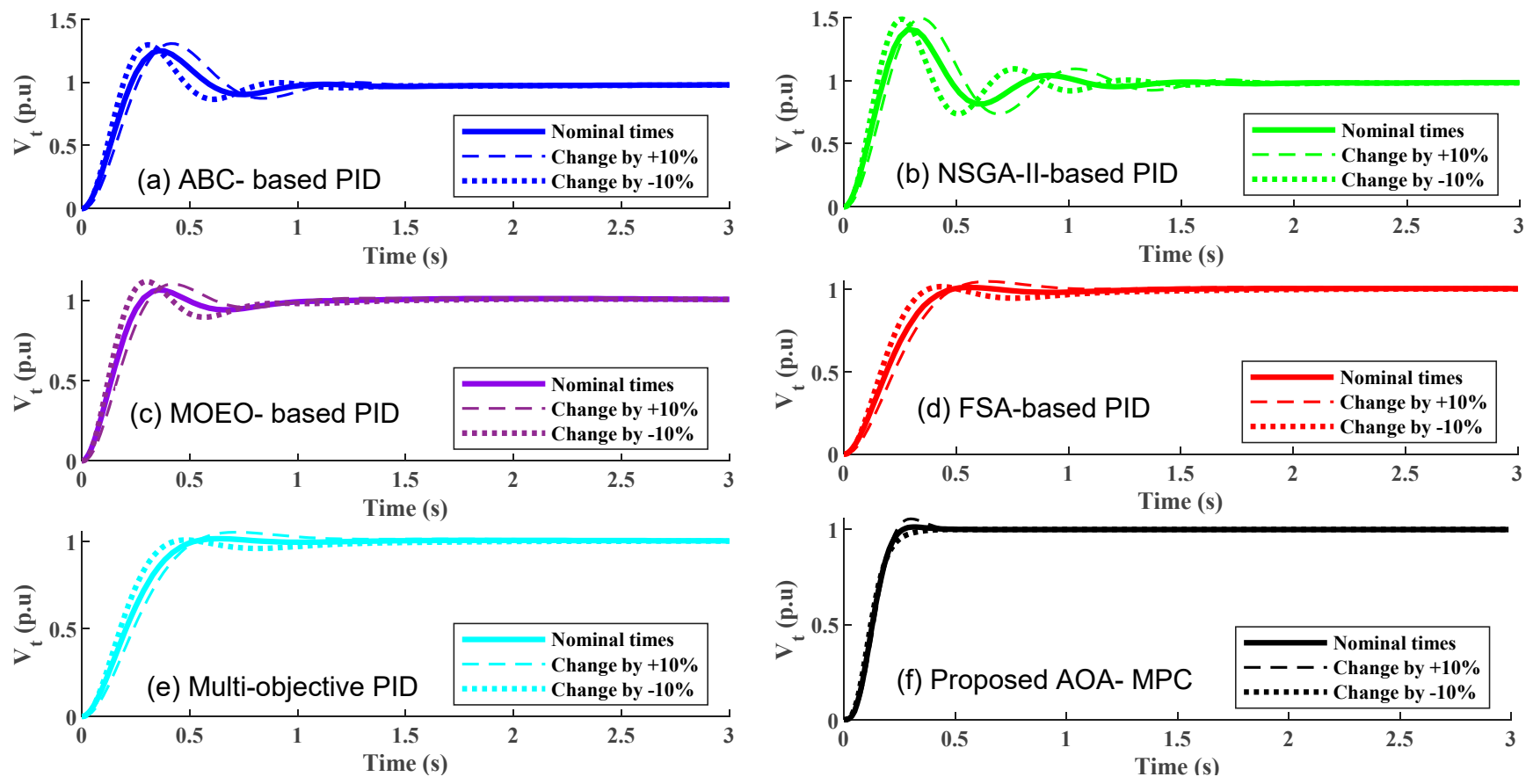

Figure 16. The terminal voltage based on the proposed AOA-based robust MPC and each technique in case of $\pm 10 \%$ variations in time constants.
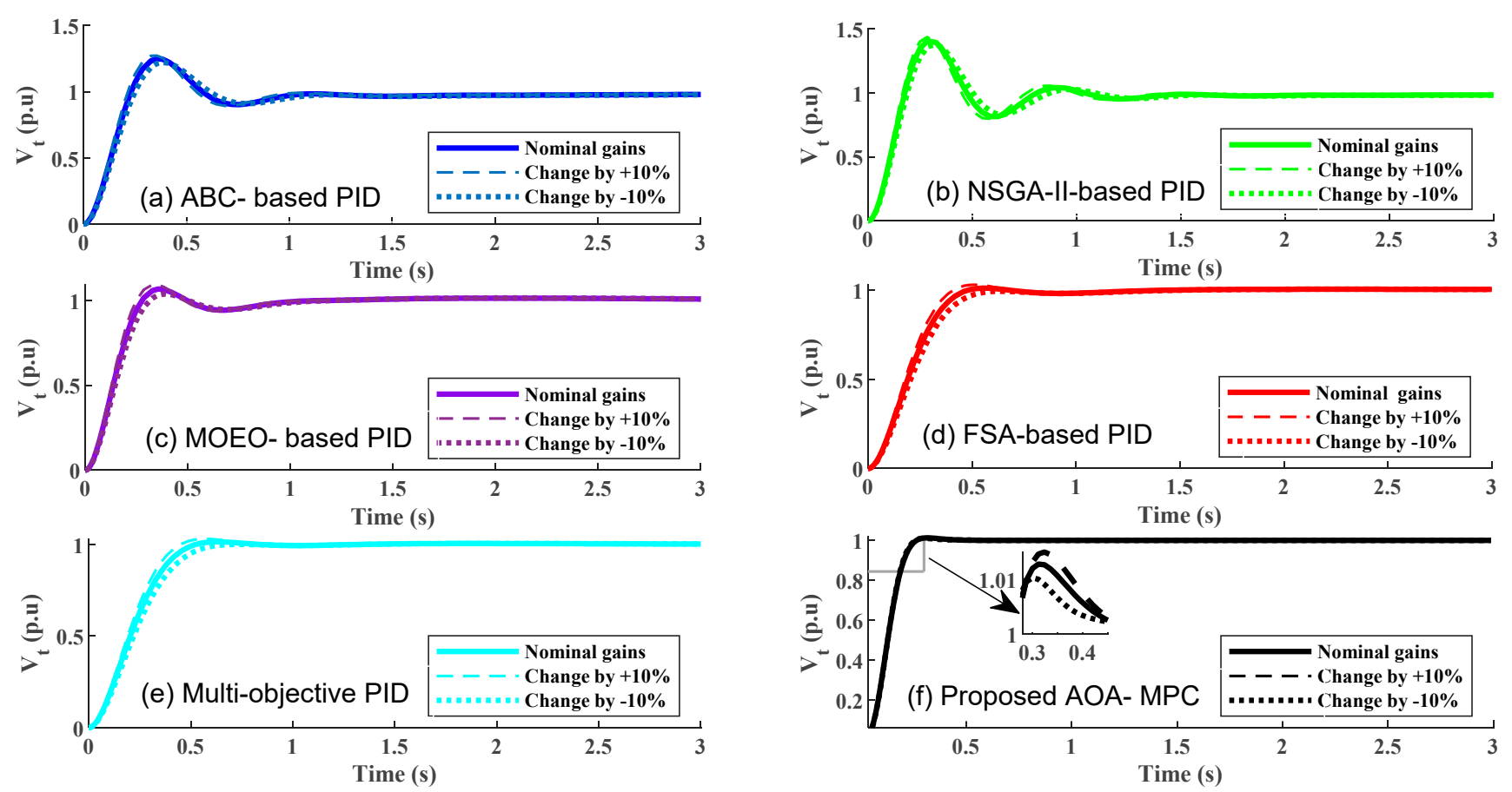

Figure 17. The terminal voltage based on the proposed AOA-based robust MPC and each technique in case of $\pm 10 \%$ variations in controller gains.

\section{Conclusions}

A new robust control strategy is introduced in this paper to design the MPC gains. Uncertainties in the AVR parameters are tackled utilizing a set of frequency-domain conditions that are capable of diminishing all expected perturbations. The gains of the MPC are tuned by the AOA as a new effective evolutionary algorithm. The tuning process handles the frequency domain conditions to confirm the stability of the perturbed system. 
The performance of the voltage response is improved based on a developed objective function that tackles the decreasing of the voltage maximum overshoot and the response settling time simultaneously. Various test cases include voltage variations and parameters uncertainty are created to emphasize the performance of the suggested AOA-based robust MPC. Furthermore, the proposed control strategy is evaluated with other methods in the literature. The results emphasize the superiority and simplicity of the suggested robust control strategy to cope with all parametric uncertainties compared with other complicated mathematical and graphical approaches. Furthermore, the proposed robust control strategy can be applied to different engineering applications in future work.

Author Contributions: Conceptualization, M.E. and M.-Q.T.; data curation, M.E. and M.-Q.T.; formal analysis, M.E., M.-Q.T., H.M.H. and R.A.T.; funding acquisition, F.A. and S.S.M.G.; investigation, M.-Q.T., H.M.H., R.A.T., F.A. and S.S.M.G.; methodology, M.E. and M.-Q.T.; project administration, H.M.H. and F.A.; resources, M.E. and F.A.; software, M.-Q.T.; supervision, M.E., H.M.H. and S.S.M.G.; validation, H.M.H., R.A.T., F.A. and S.S.M.G.; visualization, H.M.H., R.A.T., F.A. and S.S.M.G.; writing-original draft, M.E. and M.-Q.T.; writing—review and editing, H.M.H., R.A.T., F.A. and S.S.M.G. All authors have read and agreed to the published version of the manuscript.

Funding: This work was supported in part by Taif University Researchers Supporting Project number (TURSP-2020/97), Taif University, Taif, Saudi Arabia, and in part by the Ministry of Science and Technology (MOST) of Taiwan (grant numbers: MOST 110-2222-E-011-013- and MOST 110-2222-E-011-002-) and the "Center for Cyber-physical System Innovation" from The Featured Areas Research Center Program within the framework of the Higher Education Sprout Project by the Ministry of Education (MOE) in Taiwan. The research was funded by F. Albalawi.

Institutional Review Board Statement: Not applicable.

Informed Consent Statement: Not applicable.

Data Availability Statement: The data presented in this study are available on request from the corresponding author.

Acknowledgments: This work was supported in part by Taif University Researchers Supporting Project number (TURSP-2020/97), Taif University, Taif, Saudi Arabia, and in part by the Ministry of Science and Technology (MOST) of Taiwan (grant numbers: MOST 110-2222-E-011-013- and MOST 110-2222-E-011-002-) and the "Center for Cyber-physical System Innovation" from The Featured Areas Research Center Program within the framework of the Higher Education Sprout Project by the Ministry of Education (MOE) in Taiwan.

Conflicts of Interest: The authors declare no conflict of interest.

\section{References}

1. Olival, P.; Madureira, A.; Matos, M. Advanced voltage control for smart microgrids using distributed energy resources. Electr. Power Syst. Res. 2017, 146, 132-140. [CrossRef]

2. Fallahzadeh-Abarghouei, H.; Nayeripour, M.; Hasanvand, S.; Waffenschmidt, E. Online hierarchical and distributed method for voltage control in distribution smart grids. IET Gener. Transm. Distrib. 2017, 11, 1223-1232. [CrossRef]

3. Rusinaru, D.; Manescu, L.G.; Ciontu, M.; Buzatu, C.; Alba, M.; Cojoaca, A. Estimation of the maximum permissible injections of the distributed generation in the LV networks based on power quality considerations. In AIP Conference Proceeding; AIP Publishing LLC: New York, NY, USA, 2018; Volume 1982, p. 020003. [CrossRef]

4. Kundur, P.S.; Balu, N.J.; Lauby, M.G. Power system dynamics and stability. In Power System Stability and Control; CRC Press: Boca Raton, FL, USA, 2007; pp. 7-11.

5. Mosaad, A.M.; Abdelaziz, A.Y.; Attia, M.A. A Survey on Optimal Design of Controller for AVR Performance Enhancement. Manag. J. Instrum. Control. Eng. 2017, 6, 31.

6. Lodhi, R.S.; Saraf, A. Survey on PID Controller Based Automatic Voltage Regulator. Int. J. Adv. Res. Electr. Electron. Instrum. Eng. 2016, 5, 7424-7429.

7. Bahgaat, N.K.; Hassan, M.A.M. Automatic Voltage Regulator System Tuning Using Swarm Intelligence Techniques. In Advances in System Dynamics and Control; IGI Global: Hershey, PA, USA, 2018; pp. 232-252.

8. George, R.G.; Hasanien, H.M.; Badr, M.A.; Elgendy, M.A. A Comparative Study among Different Algorithms Investigating Optimum Design of PID Controller in Automatic Voltage Regulator. In Proceedings of the 2018 53rd International Universities Power Engineering Conference (UPEC), Glasgow, Scotland, 4-7 September 2018; pp. 1-6. 
9. Shayeghi, H.; Dadashpour, J. Anarchic Society Optimization Based PID Control of an Automatic Voltage Regulator (AVR) System. Electr. Electron. Eng. 2012, 2, 199-207. [CrossRef]

10. Bingul, Z.; Karahan, O. A novel performance criterion approach to optimum design of PID controller using cuckoo search algorithm for AVR system. J. Frankl. Inst. 2018, 355, 5534-5559. [CrossRef]

11. Ekinci, S.; Hekimoglu, B. Improved Kidney-Inspired Algorithm Approach for Tuning of PID Controller in AVR System. IEEE Access 2019, 7, 39935-39947. [CrossRef]

12. Kose, E. Optimal Control of AVR System with Tree Seed Algorithm-Based PID Controller. IEEE Access 2020, 8, 89457-89467. [CrossRef]

13. Zhou, Y.; Zhang, J.; Yang, X.; Ling, Y. Optimization of PID Controller Based on Water Wave Optimization for an Automatic Voltage Regulator System. Inf. Technol. Control. 2019, 48, 160-171. [CrossRef]

14. Lynser, F.B.; Sun, M.; Sungoh, M.; Taggu, N.; Konwar, P. Comparative Analysis of Different Control Schemes for DC-DC Converter: A Review. ADBU J. Electr. Electron. Eng. 2018, 2, 8-13.

15. Jumani, T.A.; Mustafa, M.W.; Hussain, Z.; Rasid, M.M.; Saeed, M.S.; Memon, M.M.; Khan, I.; Nisar, K.S. Jaya optimization algorithm for transient response and stability enhancement of a fractional-order PID based automatic voltage regulator system. Alex. Eng. J. 2020, 59, 2429-2440. [CrossRef]

16. Altbawi, S.M.A.; Bin Mokhtar, A.S.; Jumani, T.A.; Khan, I.; Hamadneh, N.N.; Khan, A. Optimal design of Fractional order PID controller based Automatic voltage regulator system using gradient-based optimization algorithm. J. King Saud Univ. Eng. Sci. 2021, in press. [CrossRef]

17. Paliwal, N.; Srivastava, L.; Pandit, M. Equilibrium optimizer tuned novel FOPID-DN controller for automatic voltage regulator system. Int. Trans. Electr. Energy Syst. 2021, 31, e12930. [CrossRef]

18. Ramezanian, H.; Balochian, S.; Zare, A. Design of Optimal Fractional-Order PID Controllers Using Particle Swarm Optimization Algorithm for Automatic Voltage Regulator (AVR) System. J. Control. Autom. Electr. Syst. 2013, 24, 601-611. [CrossRef]

19. Zamani, M.; Karimi-Ghartemani, M.; Sadati, N.; Parniani, M. Design of a fractional order PID controller for an AVR using particle swarm optimization. Control. Eng. Pract. 2009, 17, 1380-1387. [CrossRef]

20. Aghatehrani, R.; Kavasseri, R. Sliding mode control approach for voltage regulation in microgrids with DFIG based wind generations. In Proceedings of the 2011 IEEE Power and Energy Society General Meeting, Detroit, MI, USA, 24-28 July 2011; pp. $1-8$.

21. Liu, J.; Yin, Y.; Luo, W.; Vazquez, S.; Franquelo, L.G.; Wu, L. Sliding Mode Control of a Three-Phase AC/DC Voltage Source Converter Under Unknown Load Conditions: Industry Applications. IEEE Trans. Syst. Man Cybern. Syst. 2018, 48, 1771-1780. [CrossRef]

22. Spatti, D.; Da Silva, I.N.; Usida, W.F.; Flauzino, R.A. Real-Time Voltage Regulation in Power Distribution System Using Fuzzy Control. IEEE Trans. Power Deliv. 2009, 25, 1112-1123. [CrossRef]

23. Kakigano, H.; Miura, Y.; Ise, T. Distribution Voltage Control for DC Microgrids Using Fuzzy Control and Gain-Scheduling Technique. IEEE Trans. Power Electron. 2012, 28, 2246-2258. [CrossRef]

24. Spatti, D.; Da Silva, I.N.; Usida, W.F.; Flauzino, R.A. Fuzzy Control System for Voltage Regulation In Power Transformers. IEEE Lat. Am. Trans. 2010, 8, 51-57. [CrossRef]

25. Mahmud, N.; Zahedi, A. A Cooperative Operation of Novel PV Inverter Control Scheme and Storage Energy Management System Based on ANFIS for Voltage Regulation of Grid-Tied PV System. IEEE Trans. Ind. Inform. 2017, 13, 2657-2668. [CrossRef]

26. Kim, B.-G.; Rho, D.-S. Optimal Voltage Regulation Method for Distribution Systems with Distributed Generation Systems Using the Artificial Neural Networks. J. Electr. Eng. Technol. 2013, 8, 712-718. [CrossRef]

27. Saadatmand, S.; Shamsi, P.; Ferdowsi, M. The Voltage Regulation of a Buck Converter Using a Neural Network Predictive Controller. In Proceedings of the 2020 IEEE Texas Power and Energy Conference (TPEC), College Station, TX, USA, 6-7 February 2020; pp. 1-6.

28. Elsisi, M.; Aboelela, M.; Soliman, M.; Mansour, W. Design of Optimal Model Predictive Controller for LFC of Nonlinear Multi-area Power System with Energy Storage Devices. Electr. Power Compon. Syst. 2018, 46, 1300-1311. [CrossRef]

29. Hu, J.; Shan, Y.; Guerrero, J.M.; Ioinovici, A.; Chan, K.W.; Rodriguez, J. Model predictive control of microgrids-An overview. Renew. Sustain. Energy Rev. 2021, 136, 110422. [CrossRef]

30. Elsisi, M. New design of adaptive model predictive control for energy conversion system with wind torque effect. J. Clean. Prod. 2019, 240, 118265. [CrossRef]

31. Zhang, J.; Christofides, P.D.; He, X.; AlBalawi, F.; Zhao, Y.; Zhou, D. Intermittent sensor fault detection for stochastic LTV systems with parameter uncertainty and limited resolution. Int. J. Control 2018, 93, 788-796. [CrossRef]

32. Albalawi, F.; Durand, H.; Christofides, P.D. Distributed economic model predictive control with Safeness-Index based constraints for nonlinear systems. Syst. Control Lett. 2017, 110, 21-28. [CrossRef]

33. Elsisi, M.; Soliman, M.; Aboelela, M.; Mansour, W. Improving the grid frequency by optimal design of model predictive control with energy storage devices. Optim. Control Appl. Methods 2018, 39, 263-280. [CrossRef]

34. Yang, Y.; Yeh, H.-G.; Doan, S.H. Model Predictive Control via PV-Based VAR Scheme for Power Distribution Systems with Regular and Unexpected Abnormal Loads. IEEE Syst. J. 2020, 14, 689-698. [CrossRef]

35. Moradzadeh, M.; Boel, R.; Vandevelde, L. Voltage Coordination in Multi-Area Power Systems via Distributed Model Predictive Control. IEEE Trans. Power Syst. 2012, 28, 513-521. [CrossRef] 
36. Balram, P.; Tuan, L.A.; Carlson, O. Comparative study of MPC based coordinated voltage control in LV distribution systems with photovoltaics and battery storage. Int. J. Electr. Power Energy Syst. 2018, 95, 227-238. [CrossRef]

37. Wang, Z.; Wang, J.; Chen, B.; Begovic, M.M.; He, Y. MPC-Based Voltage/Var Optimization for Distribution Circuits with Distributed Generators and Exponential Load Models. IEEE Trans. Smart Grid 2014, 5, 2412-2420. [CrossRef]

38. Valverde, G.; Van Cutsem, T. Model Predictive Control of Voltages in Active Distribution Networks. IEEE Trans. Smart Grid 2013 4, 2152-2161. [CrossRef]

39. Elsisi, M. Optimal design of nonlinear model predictive controller based on new modified multitracker optimization algorithm. Int. J. Intell. Syst. 2020, 35, 1857-1878. [CrossRef]

40. Ali, H.H.; Kassem, A.M.; Al-Dhaifallah, M.; Fathy, A. Multi-Verse Optimizer for Model Predictive Load Frequency Control of Hybrid Multi-Interconnected Plants Comprising Renewable Energy. IEEE Access 2020, 8, 114623-114642. [CrossRef]

41. Wu, G.; Mallipeddi, R.; Suganthan, P.N. Ensemble strategies for population-based optimization algorithms-A survey. Swarm Evol. Comput. 2019, 44, 695-711. [CrossRef]

42. Rodríguez-Molina, A.; Mezura-Montes, E.; Villarreal-Cervantes, M.G.; Aldape-Pérez, M. Multi-objective meta-heuristic optimization in intelligent control: A survey on the controller tuning problem. Appl. Soft Comput. 2020, 93, 106342. [CrossRef]

43. Abualigah, L.; Diabat, A.; Mirjalili, S.; Elaziz, M.A.; Gandomi, A.H. The Arithmetic Optimization Algorithm. Comput. Methods Appl. Mech. Eng. 2021, 376, 113609. [CrossRef]

44. Premkumar, M.; Jangir, P.; Kumar, B.S.; Sowmya, R.; Alhelou, H.H.; Abualigah, L.; Yildiz, A.R.; Mirjalili, S. A New Arithmetic Optimization Algorithm for Solving Real-World Multiobjective CEC-2021 Constrained Optimization Problems: Diversity Analysis and Validations. IEEE Access 2021, 9, 84263-84295. [CrossRef]

45. Abualigah, L.; Diabat, A.; Sumari, P.; Gandomi, A. A Novel Evolutionary Arithmetic Optimization Algorithm for Multilevel Thresholding Segmentation of COVID-19 CT Images. Processes 2021, 9, 1155. [CrossRef]

46. Agushaka, J.O.; Ezugwu, A.E. Advanced arithmetic optimization algorithm for solving mechanical engineering design problems. PLoS ONE 2021, 16, e0255703. [CrossRef] [PubMed]

47. Ewees, A.A.; Al-Qaness, M.A.A.; Abualigah, L.; Oliva, D.; Algamal, Z.Y.; Anter, A.M.; Ibrahim, R.A.; Ghoniem, R.M.; Elaziz, M.A. Boosting Arithmetic Optimization Algorithm with Genetic Algorithm Operators for Feature Selection: Case Study on Cox Proportional Hazards Model. Mathematics 2021, 9, 2321. [CrossRef]

48. Xu, Y.-P.; Tan, J.-W.; Zhu, D.-J.; Ouyang, P.; Taheri, B. Model identification of the Proton Exchange Membrane Fuel Cells by Extreme Learning Machine and a developed version of Arithmetic Optimization Algorithm. Energy Rep. 2021, 7, $2332-2342$. [CrossRef]

49. Chauhan, S.; Vashishtha, G. Mutation-based Arithmetic Optimization Algorithm for Global Optimization. In Proceedings of the 2021 International Conference on Intelligent Technologies (CONIT), Hubbali, India, 25-27 June 2021; pp. 1-6.

50. Zheng, R.; Jia, H.; Abualigah, L.; Liu, Q.; Wang, S. Deep Ensemble of Slime Mold Algorithm and Arithmetic Optimization Algorithm for Global Optimization. Processes 2021, 9, 1774. [CrossRef]

51. Gozde, H.; Taplamacioglu, M. Comparative performance analysis of artificial bee colony algorithm for automatic voltage regulator (AVR) system. J. Frankl. Inst. 2011, 348, 1927-1946. [CrossRef]

52. Yegireddy, N.K.; Panda, S. Design and performance analysis of PID controller for an AVR system using multi-objective nondominated shorting genetic algorithm-II. In Proceedings of the 2014 International Conference on Smart Electric Grid (ISEG), Guntur, India, 19-20 September 2014; pp. 1-7.

53. Zeng, G.-Q.; Chen, J.; Dai, Y.-X.; Li, L.-M.; Zheng, C.-W.; Chen, M.-R. Design of fractional order PID controller for automatic regulator voltage system based on multi-objective extremal optimization. Neurocomputing 2015, 160, 173-184. [CrossRef]

54. Elsisi, M.; Soliman, M. Optimal design of robust resilient automatic voltage regulators. ISA Trans. 2021, 108, 257-268. [CrossRef]

55. Soliman, M.; Ali, M. Parameterization of robust multi-objective PID-based automatic voltage regulators: Generalized Hurwitz approach. Int. J. Electr. Power Energy Syst. 2021, 133, 107216. [CrossRef]

56. George, R.G.; Hasanien, H.M.; Al-Durra, A.; Badr, M.A.-L. Model Predictive Controller for Performance Enhancement of Automatic Voltage Regulator System. Int. J. Energy Convers. (IRECON) 2018, 6, 208. [CrossRef]

57. Wang, L. Model Predictive Control System Design and Implementation Using MATLAB ${ }^{\circledR}$; Springer Science \& Business Media: Berlin/Heidelberg, Germany, 2009.

58. Argoun, M.B. Frequency Domain Conditions for the Stability of Low Order Perturbed Polynomials. Am. Control Conf. 1988, 32, 913-916. [CrossRef]

59. Argoun, M.B. On the stability of low-order perturbed polynomials. IEEE Trans. Autom. Control 1990, 35, 180-182. [CrossRef]

60. Gantmacher, F.R. The Theory of Matrices; American Mathematical Society: New York, NY, USA, 1964. 